\title{
Focal mechanisms in the southern Aegean from temporary seismic networks - implications for the regional stress field and ongoing deformation processes
}

\author{
W. Friederich ${ }^{1}$, A. Brüstle ${ }^{1}$, L. Küperkoch ${ }^{3}$, T. Meier ${ }^{2}$, S. Lamara ${ }^{1}$, and Egelados Working Group ${ }^{1}$ \\ ${ }^{1}$ Ruhr-University Bochum, Institute of Geology, Mineralogy and Geophysics, Bochum, Germany \\ ${ }^{2}$ Christian-Albrechts-University Kiel, Institute of Geosciences, Kiel, Germany \\ ${ }^{3}$ BESTEC GmbH, Landau, Germany \\ Correspondence to: W. Friederich (wolfgang.friederich@rub.de)
}

Received: 12 September 2013 - Published in Solid Earth Discuss.: 24 October 2013

Revised: 17 March 2014 - Accepted: 22 March 2014 - Published: 9 May 2014

\begin{abstract}
The lateral variation of the stress field in the southern Aegean plate and the subducting Hellenic slab is determined from recordings of seismicity obtained with the CYCNET and EGELADOS networks in the years from 2002 to 2007. First motions from 7000 well-located microearthquakes were analysed to produce 540 wellconstrained focal mechanisms. They were complemented by another 140 derived by waveform matching of records from larger events. Most of these earthquakes fall into 16 distinct spatial clusters distributed over the southern Aegean region. For each cluster, a stress inversion could be carried out yielding consistent estimates of the stress field and its spatial variation. At crustal levels, the stress field is generally dominated by a steeply dipping compressional principal stress direction except in places where coupling of the subducting slab and overlying plate come into play. Tensional principal stresses are generally subhorizontal. Just behind the forearc, the crust is under arc-parallel tension whereas in the volcanic areas around Kos, Columbo and Astypalea tensional and intermediate stresses are nearly degenerate. Further west and north, in the Santorini-Amorgos graben and in the area of the islands of Mykonos, Andros and Tinos, tensional stresses are significant and point around the NW-SE direction. Very similar stress fields are observed in western Turkey with the tensional axis rotated to NNE-SSW. Intermediate-depth earthquakes below $100 \mathrm{~km}$ in the Nisyros region indicate that the Hellenic slab experiences slab-parallel tension at these depths. The direction of tension is close to east-west and thus deviates from the local NW-oriented slab dip presumably ow-
\end{abstract}

ing to the segmentation of the slab. Beneath the Cretan sea, at shallower levels, the slab is under NW-SE compression. Tensional principal stresses in the crust exhibit very good alignment with extensional strain rate principal axes derived from GPS velocities except in volcanic areas, where both appear to be unrelated, and in the forearc where compressional principal stresses are very well aligned with compressional principal strain rates. This finding indicates that, except for volcanic areas, microseismic activity in the southern Aegean is not controlled by small-scale local stresses but rather reflects the regional stress field. The lateral and depth variations of the stress field reflect the various agents that influence tectonics in the Aegean: subduction of the Hellenic slab, incipient collision with continental African lithosphere, roll back of the slab in the southeast, segmentation of the slab, arc volcanism and extension of the Aegean crust.

\section{Introduction}

The Hellenic subduction zone in the southern Aegean belongs to the seismically most active regions in Europe and has therefore been the target of many geoscientific research efforts. Seismicity is and was observed by the global seismic network, by permanent seismic observatories in Greece (National Observatory Athens (NOA), Thessaloniki, Patras and Chania universities, now the Hellenic Unified Seismic Network (HUSN)) and Turkey (Kandilli Observatory) as well as by temporary seismic deployments in the entire southern 
Aegean (Hatzfeld et al., 1993; Friederich and Meier, 2008), on Crete (Bohnhoff et al., 2005; Jost et al., 2002; Meier et al., 2004; Becker et al., 2009), in the Cyclades (Bohnhoff et al., 2004; Dimitriadis et al., 2005, 2009) and in the western Hellenic subduction zone (Haslinger, 1998; Rigo et al., 1996; Papadimitriou et al., 2010). In view of the severe seismic hazard of the region, a central aim of all research efforts is and was to promote the understanding of the current seismotectonics of the Aegean.

Seismicity observations contributed to the understanding of Aegean seismotectonics via earthquake locations which delineate active faults (Comninakis and Papazachos, 1980; Papazachos et al., 1984, 2009; Papazachos, 1990), via focal mechanisms of earthquakes which allow an (ambiguous) determination of fault planes and slip direction (e.g. Papazachos et al., 1991; Taymaz et al., 1991; Benetatos et al., 2004; Bohnhoff et al., 2005; Kiratzi et al., 2007), via observation of aftershocks which permit inferences on the size of the fault plane and the amount of slip (Drakatos and Latoussakis, 2001) and finally via stress field determinations from catalogues of focal mechanisms (Papazachos and Delibasis, 1969; Bohnhoff et al., 2005; Rontogianni et al., 2011). Besides seismicity, direct observations of plate motions by geodetic measurements (e.g. Kahle et al., 2000; McClusky et al., 2000; Reilinger et al., 2006; Hollenstein et al., 2006, 2008; Aktug et al., 2009; Floyd et al., 2010) provide constraints on today's stress field. These observations are complemented by the study of surface fault populations (e.g. Angelier, 1978), sea bathymetry measurements and reflection seismic profiles (Sachpazi et al., 1997; Bohnhoff et al., 2001).

The focus of this paper is on the lateral and depth variations of the stress field in the southeastern Aegean which we determine from focal mechanisms of shallow and intermediate-depth earthquake clusters recorded during the temporary CYCNET (Bohnhoff et al., 2004) and EGELADOS (Friederich and Meier, 2008) experiments. In the southeastern section of the Aegean, the availability of seismic data suitable for focal mechanism and stress field determinations has been particularly sparse in the past. Most previous studies rely on data from larger events recorded by teleseismic stations (Benetatos et al., 2004; Kiratzi et al., 2007). Focal mechanisms of microseismic events have been obtained by Hatzfeld et al. (1993) using data from a temporary network covering the entire southern Aegean. A notable exception is the work by Rontogianni et al. (2011) who use focal mechanisms of intermediate-depth earthquakes from previous literature and the NOA database to derive the stress field of the subducting slab in four large sectors along the Hellenic arc. Bohnhoff et al. (2005) used a focal mechanism from previous work, from a local network on Crete, from the Harvard CMT catalogue and from web sites operated by INGV and ETH for a determination of the stress field around Crete.

With the CYCNET and EGELADOS temporary networks, a dense observational coverage of the entire southern Aegean could be accomplished. A sufficient number of high-quality focal mechanisms could be determined for several clusters of microseismicity allowing us to obtain estimates of the local stress field for each cluster region separately. The inherent assumption of homogeneity of the stress field commonly made in stress tensor determinations from focal mechanisms should hence be much better fulfilled than in studies where widely distributed earthquakes are used. In this way, similar to work done in California by e.g. Hardebeck and Michael (2004), more reliable constraints on the lateral variation of the stress field can be gained. Since it is not a priori clear that focal mechanisms of microearthquakes reflect the regional stress field but may rather be controlled by small-scale local stresses, we compare the principal stress directions obtained for the shallow earthquake clusters with principal directions of the crustal strain rate field calculated from a smooth interpolation of the GPS velocity measurements of Floyd et al. (2010).

\section{Data}

The results of this study are derived from two passive, temporary seismic deployments in the Aegean Sea, the CYCNET (Bohnhoff et al., 2004) and the EGELADOS (Friederich and Meier, 2008) experiments. The CYCNET was deployed for two years beginning in autumn 2002 and covered the Hellenic volcanic arc. It consisted of in total 22 seismic stations and comprised both short-period $(1 \mathrm{~Hz})$ and $120 \mathrm{~s}$ Streckeisen broadband sensors. The EGELADOS network was a follow-up project started in autumn 2005 which covered the entire Hellenic subduction zone from the Peloponnese in the west to western Turkey in the east. EGELADOS was an amphibic network encompassing on-shore 45 Güralp $60 \mathrm{~s}$ broadband seismometers, 4 Streckeisen $120 \mathrm{~s}$ sensors, 7 Mark $1 \mathrm{~Hz}$ seismometers and 24 ocean-bottom stations equipped with $60 \mathrm{~s}$ Güralp broadband sensors and longperiod hydrophones. In addition, data of eight permanent stations of the GEOFON network equipped with Streckeisen broadband sensors could be used.

The analysis of the seismicity recorded by the two networks is described by Bohnhoff et al. (2006), Meier et al. (2004), Becker et al. (2006) and Brüstle (2012). First onsets for $\mathrm{P}$ and $\mathrm{S}$ waves were manually picked for all events. During the picking, the analysts also determined first motions of the $\mathrm{P}$ arrival for later use in focal mechanism determination. Brüstle (2012) focused her attention on the southeastern part of the Aegean and derived a minimum 1-D model for that region using the VELEST program (Kissling et al., 1994). They used this new reference model to relocate all earthquakes recorded by CYCNET and those recorded in the southeastern Aegean by EGELADOS using the nonlinear location program NonLinLoc (Lomax and Curtis, 2001; Lomax et al., 2009). In this way, a catalogue of about 7000 
earthquakes with location uncertainty of less than $20 \mathrm{~km}$ was compiled which forms the observational basis of this study.

Events from this catalogue with magnitudes larger than 3.8 were checked for suitability of focal mechanism determination by waveform matching. For about 140 of them, a reliable focal mechanisms with an acceptable waveform fit could be obtained. For all other events of the catalogue, focal mechanisms were determined from first motions using the HASHmethod of Hardebeck and Shearer (2002).

\section{Methodology}

\subsection{Moment tensors from waveform matching}

For about 140 earthquakes of magnitude larger than 3.8 recorded during the EGELADOS experiment and providing at least eight good-quality traces, we were able to obtain focal mechanism solutions using waveform fitting. The signalto-noise ratio of each trace was checked automatically during extraction from the data archive and checked visually later. Instead of performing a direct inversion for the six elements of the moment tensor, we applied a grid search. Assuming a double-couple mechanism, we searched through regularly spaced values of strike and dip of the fault plane, rake of the slip vector in the fault plane and, in addition, source depth. Epicentral source coordinates, which can be determined with much less uncertainty than source depth, were adopted from the locations previously obtained using first arrivals. For each set of angles and depths, a moment tensor with unit seismic moment was calculated and synthetic seismograms were computed for each seismic station and available component using the GEMINI code (Friederich and Dalkolmo, 1995). We took a minimum 1-D reference model that was derived from local earthquake first arrivals (Brüstle, 2012) using the program VELEST (Kissling et al., 1994). The synthetic and data traces were low-pass filtered with corner frequency of $0.1 \mathrm{~Hz}$ and the synthetic time series were adjusted to the same length and sampling rate as those of the data.

A misfit between instrument-corrected synthetic seismograms and observed seismic records was then determined as follows: first, a normalized cross-correlation function of data and synthetic traces with time lags in the range of $-60 \mathrm{~s}$ to +60 s was calculated; second, the synthetic seismogram was shifted by the time lag associated with the maximum crosscorrelation; third, an amplitude scaling factor was calculated from the ratio of the rms-amplitude of the highest amplitude data trace and the rms-amplitude of the corresponding synthetic trace, and each synthetic trace was scaled by this factor; fourth, a misfit was calculated from the summed squared difference of the corresponding time samples of data and scaled and time-shifted synthetic trace weighted by the inverse energy of the maximum amplitude data trace and by the inverse square of the maximum cross-correlation. In this way, traces with high cross-correlation yield smaller misfits.
The misfits were summed for all traces of the event. In addition, we determined the seismic moment from the square root of the ratio of the average energy of the data traces and the average energy of the synthetic traces. Misfits for each set of fault angles and depth were calculated providing a list of ranked moment tensors and source depths. The resulting best fitting focal mechanisms are depicted in Fig. 1.

With the minimum 1-D reference velocity model based on VELEST, this procedure typically provided source mechanisms by which the observed seismograms could be well reproduced in amplitude and phase by the time-shifted synthetic seismograms (Fig. 2). For some events, time shifts were large but did not vary much across different traces, indicating an error in origin time or source location or both. To obtain an agreement in phase of less than half a dominant period we added a relocation step for these events which was also done by waveform fitting. Synthetic seismograms for epicentral locations on a small rectangular grid around the original location were calculated and a rms-misfit between the traces was computed. The grid point associated with the smallest misfit was taken as the improved location.

\subsection{Focal mechanisms from first motions}

Since waveform inversion for moment tensors was only feasible for larger events with magnitudes greater than 3.8, we turned to determination of focal mechanisms from first motions to include smaller but well-recorded events. We chose an approach developed by Hardebeck and Shearer (2002) (HASH) which performs a search through a grid of fault plane normals and slip directions to find focal mechanisms which are compatible with the observed first motions. Since first-motion readings, locations and the velocity model may be erroneous, the HASH method attempts to not only determine solutions exactly fitting the first motions but also solutions which become acceptable when errors of first motions, station azimuth and take-off angles are taken into account. From the entire set of solutions the method calculates statistical properties and provides a preferred focal mechanism and estimates of the quality of the solution. The latter include the rms angular difference between the acceptable nodal planes and the preferred one and the fraction of solutions that differ by less than a given angle from the preferred one. In addition, the station distribution is ranked according to the distance of the stations from the nodal planes. Together with the number of unexplained polarities, these quality criteria allow a ranking of each obtained focal mechanism.

To use HASH with EGELADOS and CYCNET data, we searched our database of 7000 events in the southeastern Aegean established by Brüstle (2012) for suitable readings of $\mathrm{P}$ wave first motions. At least 10 first-motion readings were required. The errors of azimuth and take-off angle were estimated from the location error determined during localization with NonLinLoc (Lomax and Curtis, 2001). We rejected all focal mechanism solutions with a relative polarity error of 


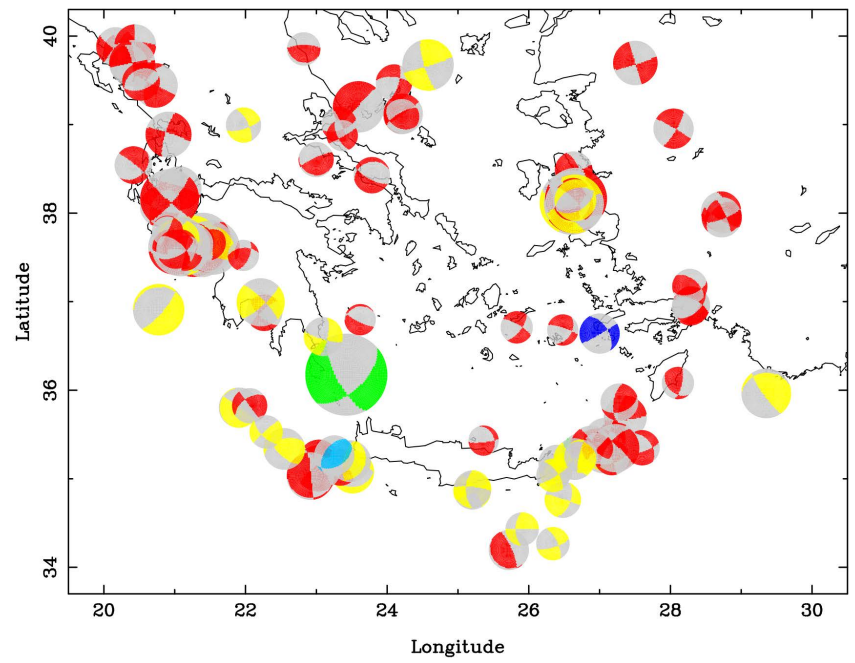

Fig. 1. Map of earthquakes for which focal mechanisms could be determined by waveform inversion. Colour of beach balls indicates source depth. Red: 0-20 km, yellow: $20-40 \mathrm{~km}$, green: $40-80 \mathrm{~km}$, blue: $80-100 \mathrm{~km}$, deep blue: $100-150 \mathrm{~km}$, magenta: $>150 \mathrm{~km}$. Size of beach ball indicates magnitude.

greater than 0.3 , a variation of the nodal planes of more than $45^{\circ}$, a fraction of less than $50 \%$ of the solutions within $30^{\circ}$ of the preferred one and a station distribution rank of less than 0.3 . From the about 7000 considered events 540 passed the quality criteria (Fig. 3). The average location error of these events is $7.5 \mathrm{~km}$. Adding the moment tensor solutions from waveform inversion provides us with a database of 680 goodquality focal mechanisms.

\subsection{Stress tensor inversion}

Focal mechanisms are typically highly variable. One reason is the variations owing to the previously mentioned uncertainties in focal mechanism determination. A further reason is the fact that the condition for compatibility of a focal mechanism with the local stress field, namely that the slip direction be parallel to the projection of the traction vector onto the fault plane (i.e. the resolved shear stress) (Gephart and Forsyth, 1984; McKenzie, 1969), is not very restrictive. Third, local stresses may exhibit small-scale variations and differ from the large-scale regional stress field.

It can be shown that the angle between the slip vector and the resolved shear stress on the fault plane only depends on four quantities (McKenzie, 1969): the directions of the principal stress axes and a dimensionless number defined by

$R=\frac{\lambda_{1}-\lambda_{2}}{\lambda_{1}-\lambda_{3}}$

where the $\lambda_{i}$ are the principal values of the stress deviator with $\sum_{i} \lambda_{i}=0$. We follow here the convention used by engineers and physicists that tensional stresses are positive and compressional stresses negative. Thus, $\lambda_{1}$ as the largest (positive) eigenvalue is associated with the least compressive and $\lambda_{3}$ with the most compressive stress. $R=0$ implies $\lambda_{1}=\lambda_{2}$ and $\lambda_{3}=-2 \lambda_{1}$ and indicates a biaxial compressive stress regime. For $R=0.5, \lambda_{2}=0$ and $\lambda_{3}=-\lambda_{1}$ indicating a plane deviatoric stress state. In the case of $R=1, \lambda_{2}=\lambda_{3}$ and $\lambda_{3}=-0.5 \lambda_{1}$ signifying a biaxial tensional stress regime.

We implemented an approach that combines the grid search proposed by Gephart and Forsyth (1984) and an approach by Michael (1984). For principal stress directions and $R$ value varying on a regular grid, we determine the angle between slip vector and resolved shear stress on the fault plane for each focal mechanism entering the stress tensor determination. The angles are summed to yield a misfit for each specific stress tensor. The stress tensors are ranked according to this misfit and the best fitting solution is the preferred stress tensor. However, since focal mechanisms contain substantial uncertainty, we need meaningful confidence regions of the preferred solution. They can be obtained by a bootstrap procedure (Efron and Tibshirani, 1986) which was applied to stress tensor determination by Michael (1987). In principle, one should repeat the experiment with new earthquakes in the same region many times and then observe the variation of the preferred solution. Since this is impossible, one resorts to a random resampling of the available data set by randomly picking $N$ focal mechanisms out of the original $N$ ones. Some focal mechanisms will occur more than one time and some will be absent. By finding the preferred solution for many of these randomly picked data sets of focal mechanism we can obtain an estimate of the variability of the preferred solution. The $p \%$ confidence limit is obtained by finding the $p \%$ of the stress tensors which are closest to the one determined from the original data set. To calculate the similarity of two tensors, we follow Michael (1984) who uses a normalized scalar product of two tensors defined as follows:

$$
S=\frac{\sum_{i=1,3} \sum_{j=1,3} M_{i j} N_{i j}}{\sqrt{\sum_{i=1,3} \sum_{j=1,3} M_{i j}^{2}} \sqrt{\sum_{i=1,3} \sum_{j=1,3} N_{i j}^{2}}} .
$$

The confidence limits of the principal axes are visualized by plotting the directions of the principal axes of the $p \%$ closest solutions into binned lower-hemisphere Schmidt projections and colour coding each bin according to its relative frequency of occurrence in the set of solutions. In addition, we display the frequency distribution of $R$ values occurring in the $p \%$ closest solutions.

The stress tensor itself is graphically represented by visualizing the dependency of deviatoric tangential and normal stress on the orientation of the surface they act on. Surface normals are discretized as bins on a sphere, and the values of tangential and normal stresses are represented by assigning a colour code to each bin. A graphical display is finally realized by a Schmidt projection of the lower half of the binned and colour-shaded sphere onto the earth's surface. We use separate Schmidt projections for the absolute value of tangential stress and the signed value of deviatoric normal 

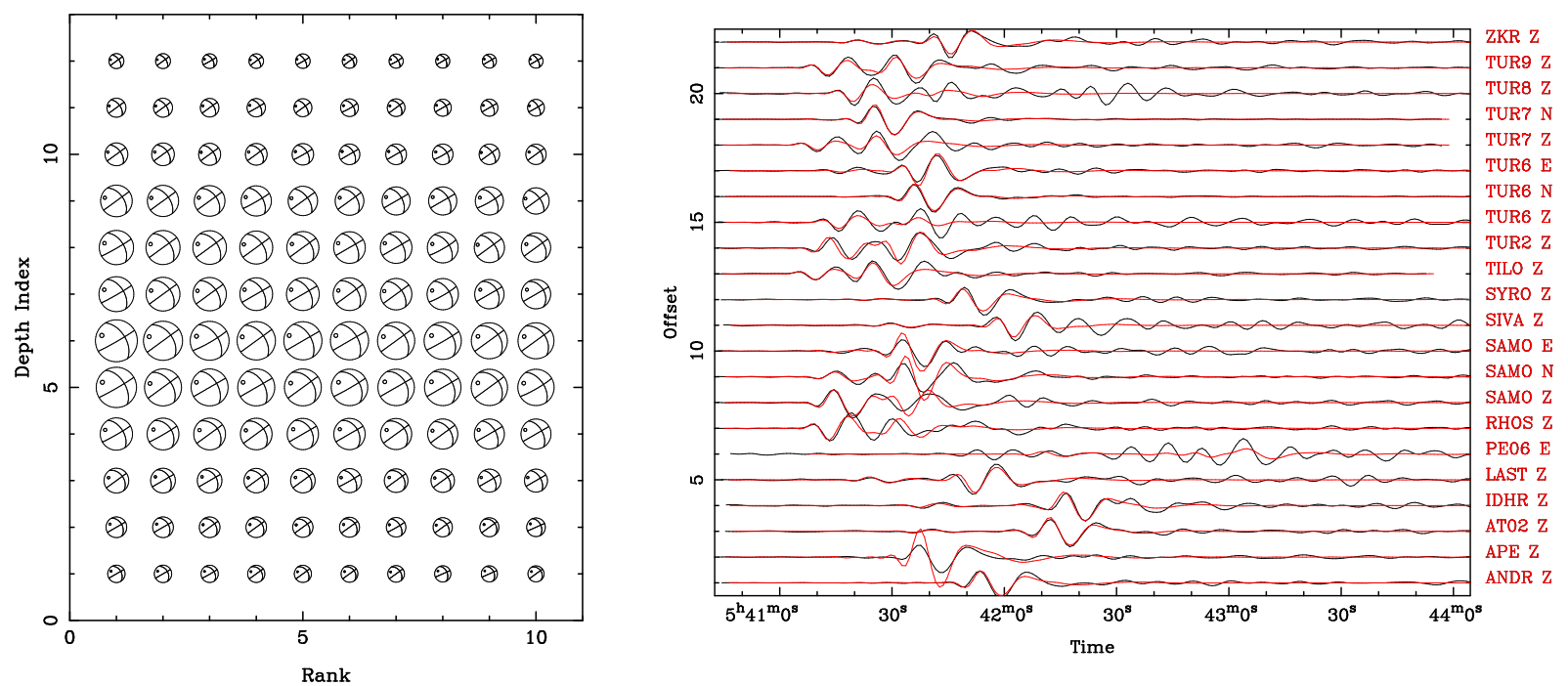

Fig. 2. Left: example of ranking of source mechanisms for an intermediate-depth earthquake at $135 \mathrm{~km}$ depth. Each row of beach balls displays the 10 best solutions for a given source depth. The size of the beach ball is inversely proportional to the waveform misfit. Depths range from $160 \mathrm{~km}$ at the bottom to $100 \mathrm{~km}$ at the top. The small circle in the beach balls indicates the location of the tension axis. Right: example of the waveform fit for the intermediate-depth earthquake. Data are shown as black lines, shifted synthetic traces as red lines. Relative amplitudes of data and synthetic traces are correctly reproduced.
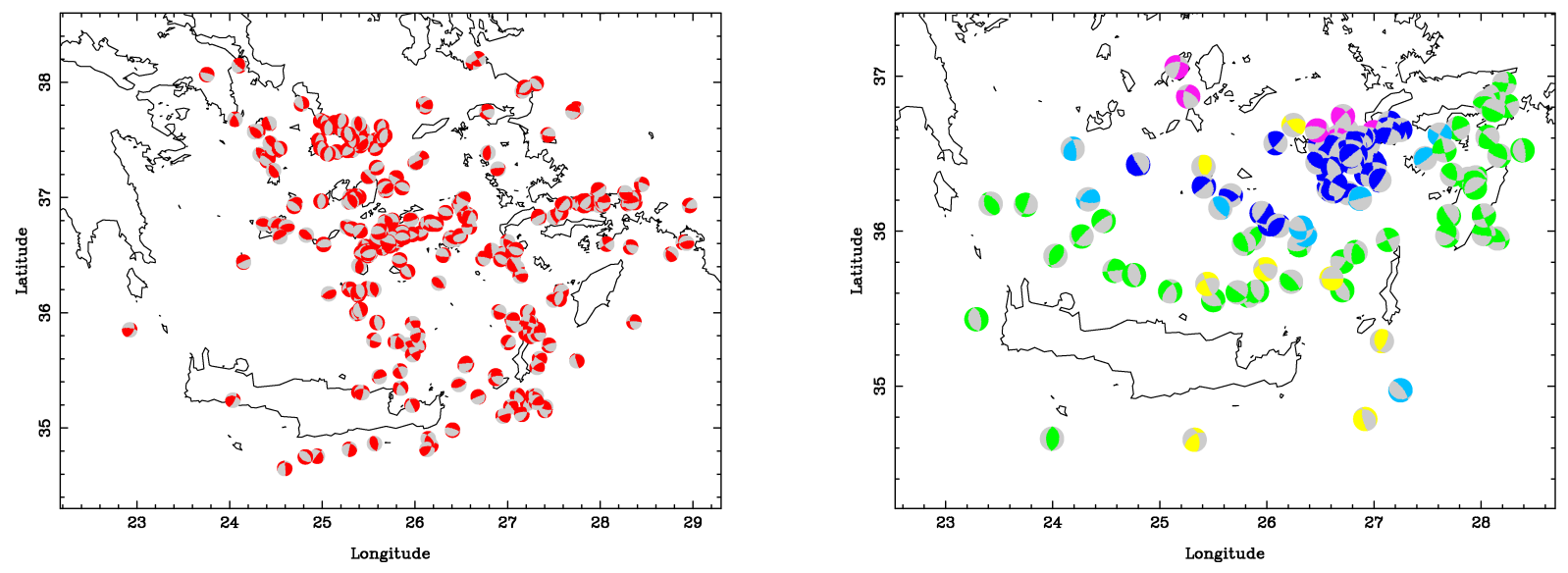

Fig. 3. Map of earthquakes for which focal mechanisms could be determined from first motions. Left: shallow earthquakes. Right: earthquakes deeper than $20 \mathrm{~km}$. Colour of beach balls indicates source depth. Red: 0-20 km, yellow: 20-40 km, green: 40-80 km, blue: 80-100 km, deep blue: $100-150 \mathrm{~km}$, magenta: $>150 \mathrm{~km}$.

stress. In both cases the deviatoric stress tensor is normalized by setting the largest eigenvalue $\lambda_{1}$ to 1 . For tangential stress, the principal stress axes show up as places of zero tangential stress whereas for normal deviatoric stress, the principal stress directions lie at the extrema of normal stress. According to our sign convention, positive (negative) deviatoric normal stress indicates tension (compression). While tangential stress only depends on deviatoric stress, the true normal stress differs from deviatoric normal stress by the isotropic pressure which cannot be determined by stress inversion from focal mechanisms.

\section{Results and discussion}

Stress inversion from focal mechanisms builds on the assumption of homogeneous stress within the region spanned by the associated earthquakes. For this reason, stress inversion studies attempt to divide the region of interest into small subregions under the constraint that they still contain a sufficient number of focal mechanisms. Because of the limited number of focal mechanisms available in many studies, these subregions have to be chosen fairly large, making the validity of the homogeneity assumption debatable. In this study, the large number of high-quality focal mechanisms and the 
clustering of seismicity allows a determination of the stress field separately for each cluster. Homogeneity of the stress field is much better fulfilled in this case than for regionally distributed seismicity. In the following we will separately present and discuss results obtained for shallow seismicity that provide constraints on the crustal stress field and results obtained for intermediate-depth earthquakes from which we get information on the stress field in the Hellenic slab.

\subsection{Stress state of the Aegean crust from shallow seismicity}

We have grouped the shallow seismicity (depth less than $20 \mathrm{~km}$ ) into 12 clusters as depicted in Fig. 4: Iraklion basin, Kamilonisi basin, Gulf of Gökova, Kos, Astypalea, Mykonos, Amorgos, Columbo volcano, South and North Karpathos, Sigacik and Zante (not shown on map). In this way, average deviations of the slip direction from the resolved shear stress on the fault plane did not exceed $28^{\circ}$. The resulting stress solutions allow a fair image of the distribution of stress in the southeastern Aegean at the crustal level (Table 1). In general, the compressional principal axes dip steeply while the tensional and intermediate axes are subhorizontal. Notable exceptions are the clusters at Zante, SKarpathos and Gökova. In the majority of cases, the stress ratio $R$ is less than 0.5 indicating a larger magnitude of compressive principal stress compared to tensional principal stresses. Unfortunately, the stress ratio $R$ does not allow any inferences on the ratio of compressive to tensional stress because it is independent of the isotropic part of the stress tensor. Hence, for example, a dominant vertical compressive principal stress could be caused either by gravity stresses inside a vertically layered elastic crust or by additional compressive stress created by a magma upwelling in the mantle. In both cases, we would obtain the same stress ratio of $R=0$. However, there are also clusters with $R \neq 0$. If $R<0.5$, the compressive principal stress dominates but tensional and intermediate principal stresses differ, indicating a deviation of the stress field from that of a vertically layered elastic crust. Is $R>0.5$, the tensional principal stress is larger than the compressive ones. Both cases indicate the action of some tectonic force on the crust.

In the following we discuss the results of focal mechanism determination and stress inversion for each cluster. They are visualized by a composite figure displaying the distribution of $\mathrm{T}$ and $\mathrm{P}$ axes of the focal mechanisms, the $80 \%$ confidence regions of the three principal stress axes, the frequency distribution of $R$ values among the $80 \%$ stress solutions closest to the preferred one and a graphical representation of the stress tensor.

\subsubsection{Amorgos and Andros-Mykonos}

The biggest number of focal mechanisms in this study is available for the Amorgos fault zone region. The 72 focal

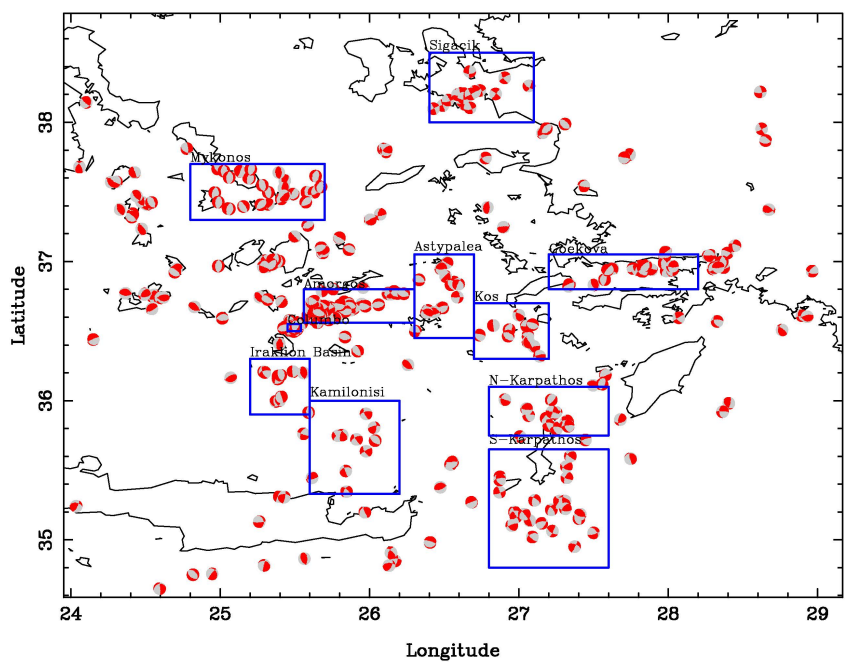

Fig. 4. Shallow earthquake locations with focal mechanisms and definition of cluster regions.

mechanisms can be explained by a single stress solution with a small average angular misfit of $23.6^{\circ}$ (Fig. 5). The $P$ axes of the focal mechanisms tend to dip steeply while the $\mathrm{T}$ axes are close to horizontal with an accumulation in the $\mathrm{N}-\mathrm{S}$ direction. The tensional and compressional stress axes are well determined with concentrated confidence regions while the intermediate stress axis is less well constrained. Compressional stress slightly dominates and is directed subvertical with a dip of $62^{\circ}$. The tensional axis is close to horizontal with a dip of $12^{\circ}$. Its orientation is about NNW-SSE with an azimuth of $155^{\circ}$. The distribution of stress ratio values also indicates a well-constrained value of around 0.3. Stress directions and stress ratio indicate a normal faulting regime. Maximum tangential stress is reached either on rather steeply SE-dipping planes striking SW-NE or W-E-striking planes dipping at about $45^{\circ}$ towards north. These results are consistent with the general SW-NE trend of the Amorgos fault zone and the preferred occurrence of normal faulting earthquakes. A similar result with a tensional axis slightly rotated to the west was found for the Andros-Mykonos cluster described in the Appendix (Fig. A6).

\subsubsection{Columbo volcano, Kos-Nisyros and Astypalea}

At the southwestern tip of the Amorgos fault zone and northeast of Santorini sits Columbo volcano which exhibited high seismic activity during the observation period of the EGELADOS and CYCNET deployments (Fig. 6). As for the Amorgos cluster the $\mathrm{P}$ axes concentrate in the centre of the focal sphere while the $T$ axes tend to appear in the outer parts with a large spread of directions. As a consequence, only the compressional stress axis can be well determined. The $80 \%$ closest bootstrap solutions exhibit a large spread of directions for both tensional and intermediate stress axis. In contrast, the $R$ values concentrate at very low values with 
Table 1. Summary of stress inversion results for shallow earthquake clusters. Clusters are ordered according to the number of available focal mechanisms. Azimuth is measured in degrees from north over east.

\begin{tabular}{|c|c|c|c|c|c|c|c|c|c|}
\hline \multirow[t]{2}{*}{ Cluster } & \multirow[t]{2}{*}{$\begin{array}{r}\text { Number of } \\
\text { focal } \\
\text { mechanisms }\end{array}$} & \multirow[t]{2}{*}{$\begin{array}{r}\text { Average } \\
\text { misfit/deg }\end{array}$} & $\begin{array}{r}\text { Dip/ } \\
\text { deg }\end{array}$ & $\begin{array}{r}\text { Azimuth/ } \\
\text { deg }\end{array}$ & $\begin{array}{r}\text { Dip/ } \\
\text { deg }\end{array}$ & $\begin{array}{r}\text { Azimuth/ } \\
\text { deg }\end{array}$ & $\begin{array}{r}\text { Dip/ } \\
\text { deg }\end{array}$ & $\begin{array}{r}\text { Azimuth/ } \\
\text { deg }\end{array}$ & \multirow[t]{2}{*}{$R$} \\
\hline & & & \multicolumn{2}{|c|}{ Tensional axis } & \multicolumn{2}{|c|}{ Interm. axis } & \multicolumn{2}{|c|}{ Compr. axis } & \\
\hline Amorgos & 72 & 23.6 & 12 & 155 & 25 & 59 & 62 & 268 & 0.3 \\
\hline Columbo & 40 & 26.9 & 13 & 0 & 20 & 95 & 65 & 239 & 0.0 \\
\hline Zante & 29 & 28.0 & 43 & 90 & 34 & 320 & 27 & 209 & 0.1 \\
\hline Mykonos & 23 & 7.4 & 10 & 309 & 11 & 217 & 75 & 82 & 0.2 \\
\hline S-Karpathos & 19 & 27.7 & 43 & 311 & 8 & 48 & 46 & 147 & 0.1 \\
\hline Sigacik & 21 & 14.0 & 0 & 25 & 11 & 295 & 79 & 115 & 0.9 \\
\hline Gökova & 16 & 23.9 & 38 & 20 & 5 & 286 & 52 & 190 & 0.3 \\
\hline N-Karpathos & 15 & 11.6 & 0 & 47 & 26 & 317 & 64 & 137 & 0.5 \\
\hline Astypalea & 14 & 22.1 & 29 & 40 & 14 & 302 & 58 & 189 & 0.0 \\
\hline Iraklion & 10 & 11.8 & 31 & 270 & 10 & 174 & 58 & 69 & 0.7 \\
\hline Kos & 10 & 17.6 & 17 & 149 & 25 & 248 & 59 & 29 & 0.0 \\
\hline Kamilonisi & 9 & 20.8 & 6 & 72 & 36 & 165 & 54 & 332 & 0.8 \\
\hline
\end{tabular}
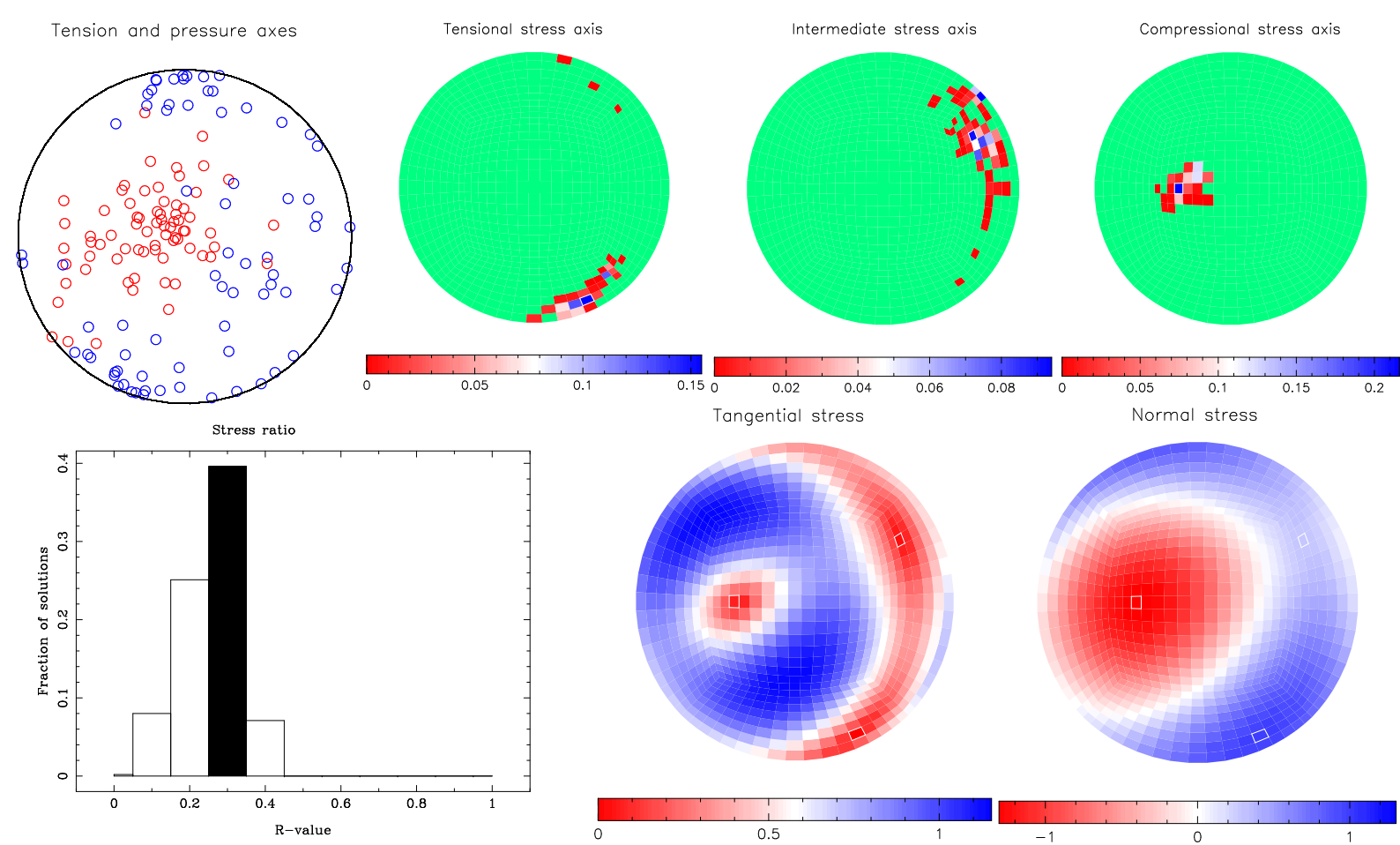

Fig. 5. Results of stress inversion for cluster of shallow earthquakes near Amorgos. Top row from left to right: location of tension (blue circles) and pressure axes (red circles) of focal mechanisms, $80 \%$ confidence region for least compressive (deviatoric tensional), intermediate and most compressive (deviatoric compressive) principal stress axes. Bottom row from left to right: distribution of $R$ values for best $80 \%$ of stress tensor solutions, absolute value of tangential stress and signed normal stress versus surface normal.

a sharp maximum at $R=0$. The best fitting stress solution with an average angular misfit of $26.9^{\circ}$ is characterized by a steeply dipping compressive axis and degenerate tensional principal stresses. Hence, there is no preferred tensional direction. Planes of maximum shear stress can strike in any direction. One could speculate that magma upwelling from the mantle puts the crust under vertical compressive stress without any preference for near-horizontal tensional stress. However, as discussed before, the stress solution does not enable us to make any statements about the ratio of true compressive to tensional principal stresses. Very similar solutions 


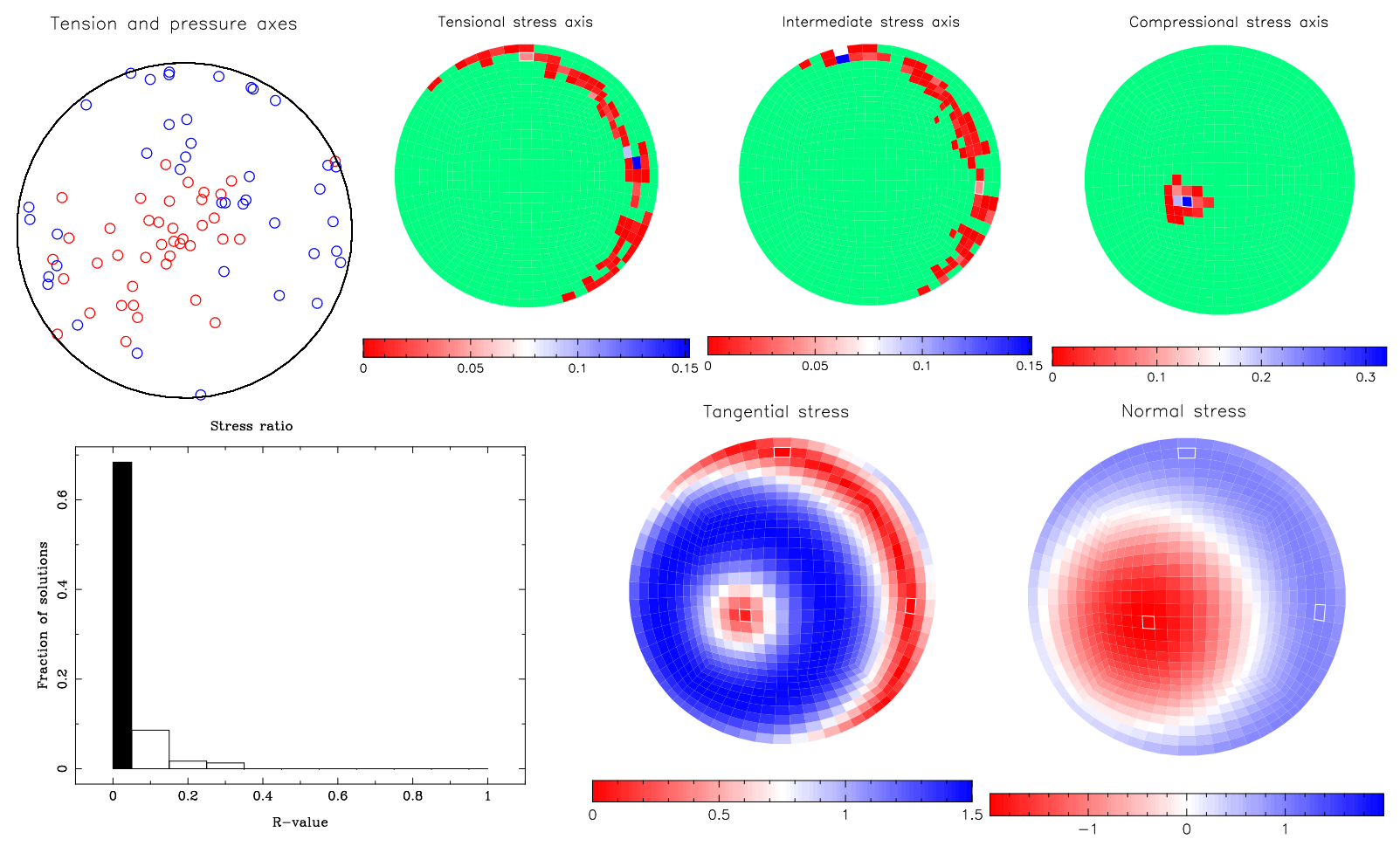

Fig. 6. Results of stress inversion for cluster of shallow earthquakes near Columbo volcano. Explanation of subfigures is as in Fig. 5 .

were obtained for the clusters near Kos-Nisyros and Astypalea which are described in the Appendix.

\subsubsection{Karpathos, Iraklion and Kamilonisi basin}

The focal mechanisms of the earthquakes around Karpathos can only be well explained by a stress tensor if they are split into two subregions, one encompassing the events north of Karpathos and one containing the events surrounding the southern part of Karpathos. Results for the two regions are very different. For the events south of Karpathos (Fig. 7), the compressional stress axis is well constrained while the bootstrap solutions exhibit a strong spread for the other two axes. The distribution of $R$ values is very narrow with a clear maximum at $R=0.1$ indicating a degeneracy of the tensional and intermediate principal stresses. The compressional axis dips at only $46^{\circ}$ which is the second smallest value among all clusters considered. The direction of the compressional axis is about SE-NW (azimuth $147^{\circ}$ ) and nicely coincides with the local direction of subduction. This finding suggests that the stress field in the Aegean plate south of Karpathos is modified by the downgoing African lithosphere which exerts some horizontal pressure on the upper plate and hence rotates the compressional stress axis from its subvertical orientation found for the other event clusters. Due to the degeneracy of the tensional principal stresses planes of maximum shear stress may strongly vary in strike and dip.
The situation is very different for the earthquakes north of Karpathos (Fig. 8) where the compressional axis moves back to a dip of $64^{\circ}$ with about the same azimuth as south of Karpathos. Tensional and intermediate principal stresses are clearly different. All principal axes have small $80 \%$ confidence regions. The distribution of $R$ values is narrow with a maximum at 0.5 . The tensional axis is exactly horizontal with an NE-SW orientation parallel to the Hellenic arc. Planes of maximum shear stress have intermediate dip and strike either roughly $\mathrm{N}-\mathrm{S}$ or E-W. Apparently, the stress state in the Aegean plate significantly changes with distance from the plate contact from dominating subduction parallel compression to dominating tension perpendicular to the subduction direction. Arc parallel tension is also found for the Iraklion and Kamilonisi basins (Figs. A3 and A4) as described in more detail in the Appendix.

\subsubsection{Gökova graben and Sigacik basin}

The Gökova graben is located at the easternmost tip of the Hellenic subduction zone on the transition from the Aegean microplate to the Anatolian plate. GPS observations in this area (Reilinger et al., 2010) indicate a significant relative motion between the Aegean and western Turkey which may influence the regional stress field. Our stress analysis (Fig. 9) exhibits a well-defined compressional axis, a less well defined tensional axis and a variable intermediate axis. The stress ratio $R$ shows a fairly concentrated distribution around 

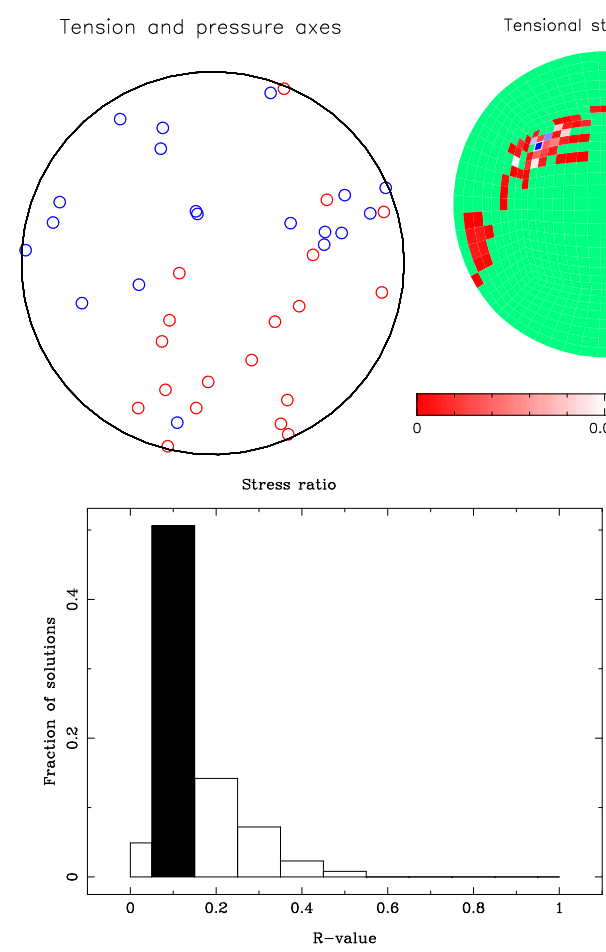

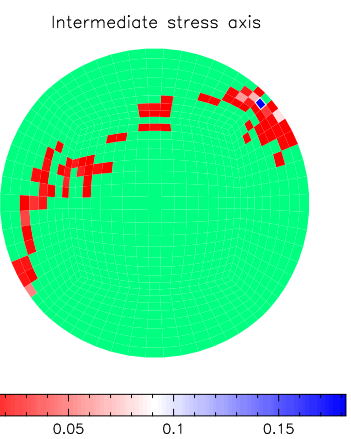

Tangential stress
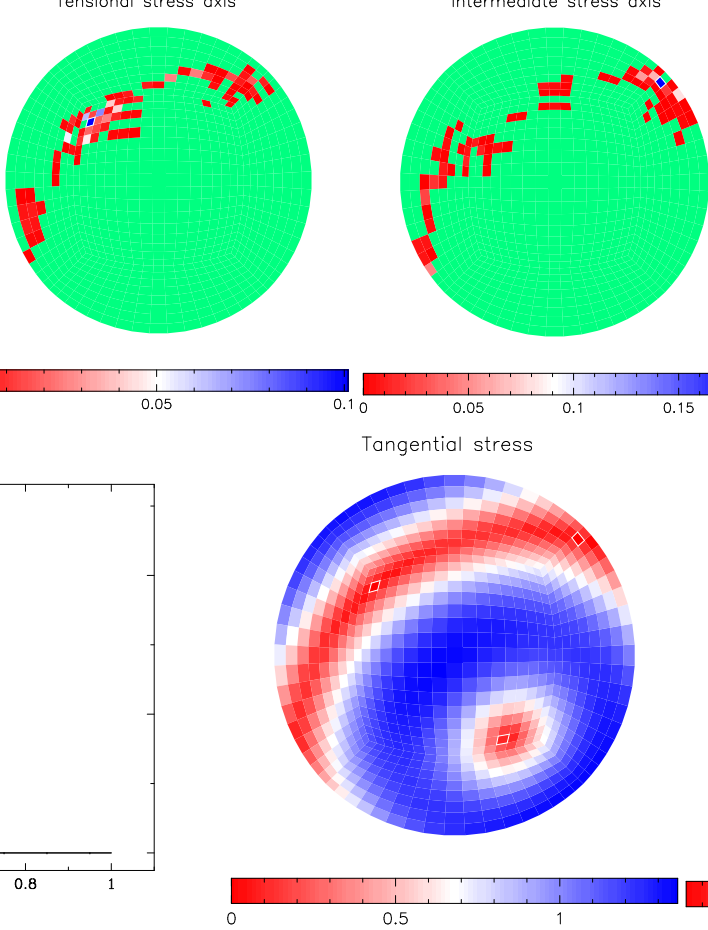

Fig. 7. Results of stress inversion for cluster of shallow earthquakes south of Karpathos. Explanation of subfigures is as in Fig. 5.
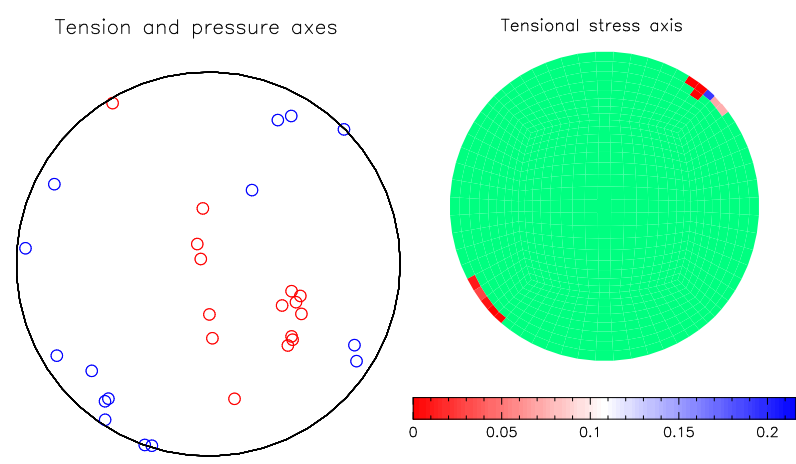

tress ratio

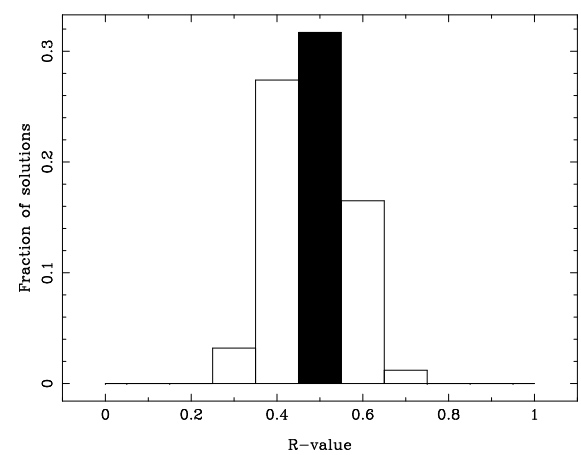

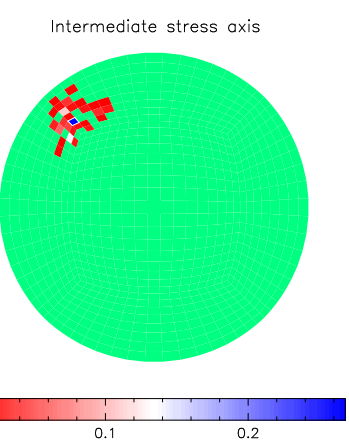

Tangential stress
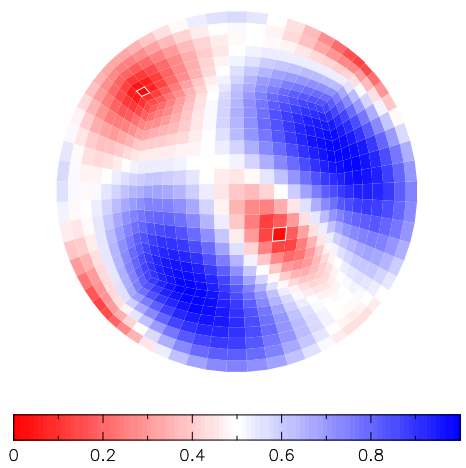
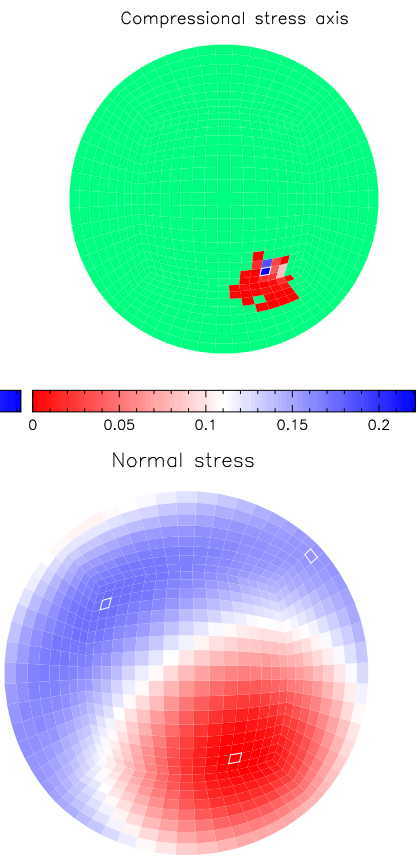

$-1$ 


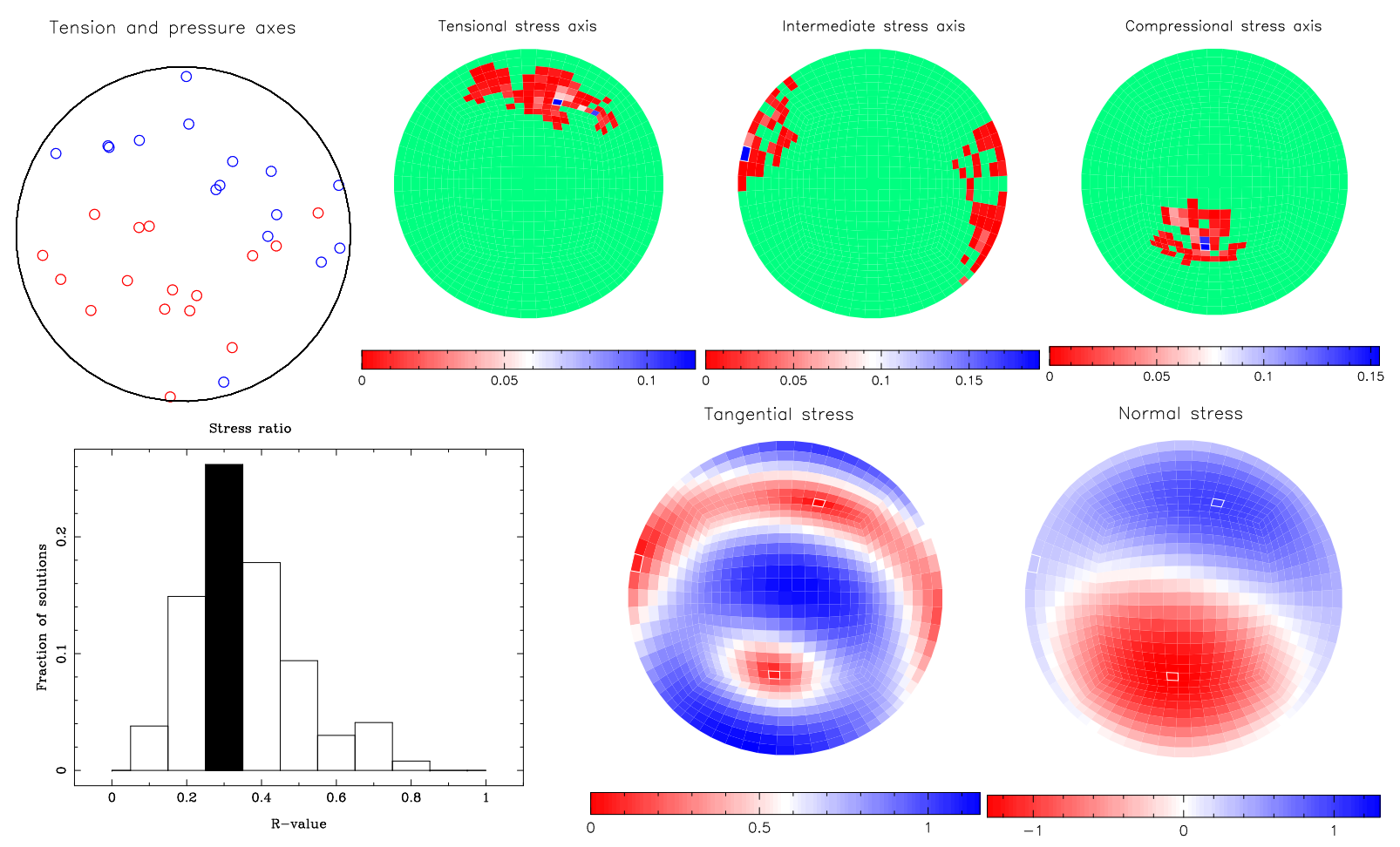

Fig. 9. Results of stress inversion for cluster of shallow earthquakes near Gökova. Explanation of subfigures is as in Fig. 5.

0.3. Thus, tensional and intermediate principal stresses significantly differ. The dip of the compressional axis is relatively small $\left(52^{\circ}\right)$ with a $\mathrm{N}-\mathrm{S}$ orientation and suggests some influence of subduction on the stress field. The tensional axis also dips by $38^{\circ}$ with a NNE-SSW orientation. Planes of maximum shear stress are either horizontal or steeply dipping striking roughly E-W. One may speculate that the superposition of stresses related to subduction and to the northward motion of western Turkey relative to the central Aegean (Reilinger et al., 2010) controls the regional stress field. The stress field in the Sigacik basin (Fig. A5) that exhibits a very clearly constrained horizontally oriented tensional axis is described in the Appendix.

\subsubsection{Zante}

The cluster in Zante is very close to the western Hellenic subduction front along western Peloponnese. The stress determination for these events (Fig. 10) results in a well-constrained compressional stress axis dipping subhorizontal at an angle of $27^{\circ}$ and less well defined tensional and intermediate axes. A small stress ratio $R=0.1$ indicates nearly degenerate tensional and intermediate principal stresses. The azimuth of the compressional axis is $209^{\circ}$ which is close to the SSW-NNE direction. Planes of maximum shear stress strike WNW-ESE with either very small or very large dip. The findings suggest a strong influence of subduction on the stress field. The subduction direction is roughly parallel to the azimuth of the compressional axis. Its small dip also indicates the action of horizontal pressure exerted by the subducting slab at the plate contact. Otherwise, we would expect a steeply dipping compressional axis.

\subsubsection{Overview of the stress field in the Aegean micro-plate}

In order to provide a comprehensive picture of the variation of the stress field in the Aegean micro-plate we plot the stress tensor visualizations showing normal stress into a map of the southeastern Aegean region (Fig. 11). Dark blue colours indicate tensional normal stress and dark red colours signify compressional normal stress. We observe a tensional stress parallel to the Hellenic arc from the Iraklion basin in the west over the Kamilonisi basin to north Karpathos in the east. This behaviour can be explained by the fan-like spread of velocity vectors in the southern part of the Aegean microplate which is mainly caused by the rollback of the Hellenic slab in the southeastern Aegean (Reilinger, 2010). A similar observation was made by Benetatos et al. (2004) based on averaged focal mechanisms of larger-magnitude earthquakes $(M>5)$. The stress fields at Zante, South Karpathos and also Gökova appear to be influenced by nearby subduction processes which exert a subhorizontal pressure on the upper plate leading to a rotation of the compressional stress axis towards smaller dips. This effect is most pronounced for the Zante cluster. The stress field in the volcanic arc could be 

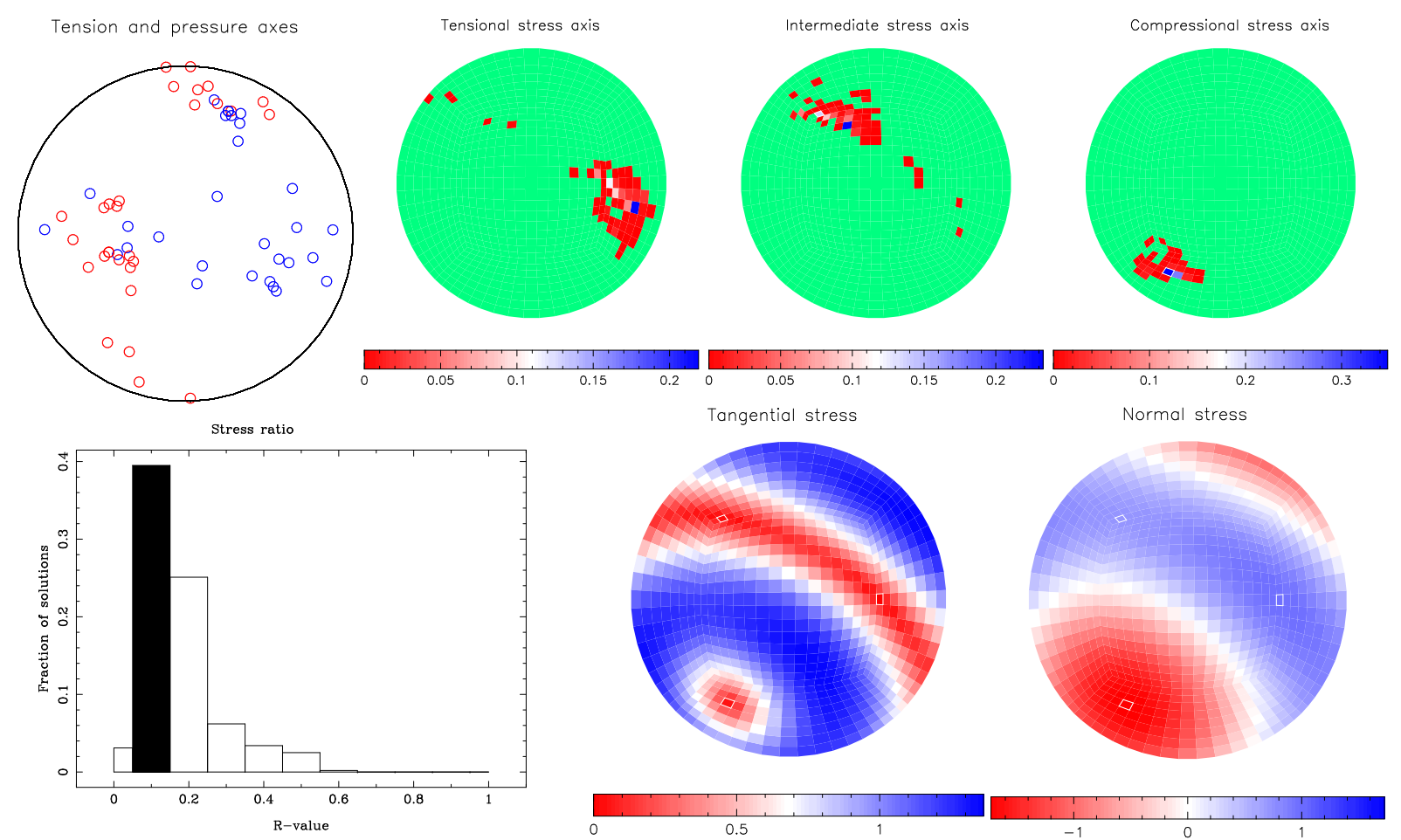

Fig. 10. Results of stress inversion for cluster of shallow earthquakes near Zante. Explanation of subfigures is as in Fig. 5.

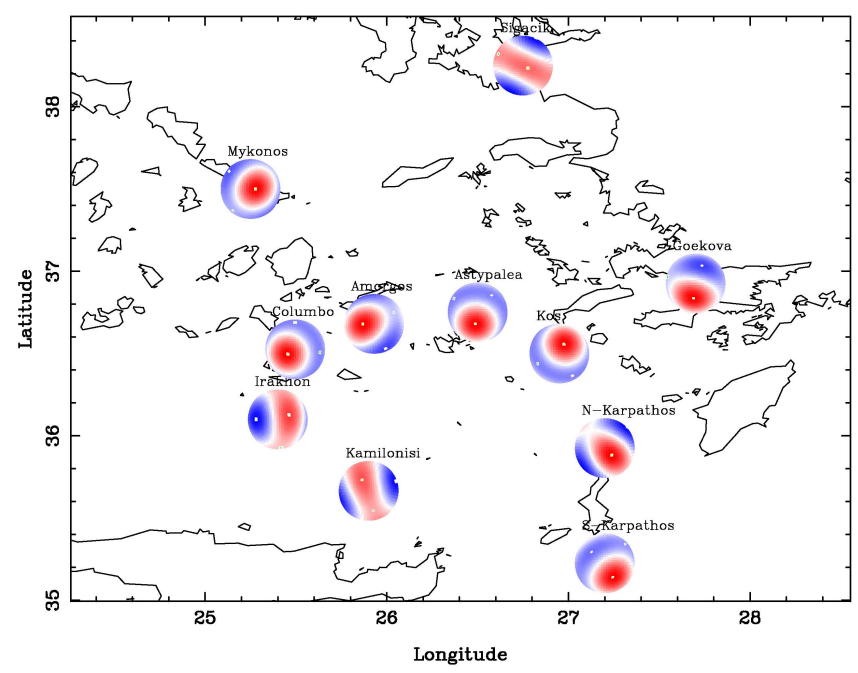

Fig. 11. Stress solutions visualized by distribution of normal stress versus fault plane normal.

influenced by magmatic processes in the mantle because the stress solutions exhibit dominant subvertical compressional axes with nearly degenerate tensional and intermediate principal stresses. The exception is the Amorgos fault zone where a NNW-SSE oriented tensional stress direction was identified. Nearly the same trend (NW-SE) of the tensional axis is observed for the Andros-Tinos-Mykonos cluster in the northwest of Amorgos while tensional stresses are oriented
NNE-SSW in the Sigacik and Gökova area. A similar observation is made by Benetatos et al. (2004) who find focal mechanisms with generally $\mathrm{N}-\mathrm{S}$ directed $\mathrm{T}$ axes in the region north of the volcanic arc. However, our results indicate a systematic rotation of the tensional stress axis which is reflected in the curved shape of graben systems extending from Mykonos to Sigacik in the north and from Amorgos to Gökova further in the south.

\subsubsection{Comparison with the GPS-derived regional strain rate field}

Since in this study stress tensors have been obtained for local clusters of microearthquakes, it is not a priori clear that they represent the regional stress field. The fault area ruptured by microearthquakes analysed in this study may be well below $1 \mathrm{~km}^{2}$. For example, according to Wells and Coppersmith (1994), the rupture area of a magnitude 3 earthquake is about $0.2 \mathrm{~km}^{2}$. Hence, our stress solutions might well reflect local stresses expected to exhibit small-scale spatial variations and potentially being unrelated to the large-scale regional stress field.

There are two major arguments against this proposition: first, if microearthquakes were controlled by local stresses on a scale of $1 \mathrm{~km}$ or less, we would not have been able to find stress solutions for an entire cluster with such small angular misfits (Table 1). Second, the principal stress axes obtained 
in this study align very well with the principal directions of the regional strain rate field as will be shown in the following.

For comparison of stress and strain rates, we start out with GPS velocities obtained by Floyd et al. (2010) and compute a continuous velocity field using a method and associated computer program developed by Tape et al. (2009). The method uses a representation of the velocity field by multiscale spherical wavelets and determines wavelet coefficients by a least-squares fit of theoretical to observed velocities. We use wavelets of order 3 to 8 with half-widths ranging from $1400 \mathrm{~km}$ down to $40 \mathrm{~km}$. The GPS velocities (Fig. 12, left) can be fit by the continuous velocity field in the southeastern Aegean with residuals of less than $5 \%$ (Fig. 12, right). There appears to be no point in defining blocks, as potentially discontinuous motion by a finite number of blocks does not result in a better fit of the observed velocities (Floyd et al., 2010). The program of Tape et al. (2009) also computes the components of the symmetric strain rate tensor by differentiating the velocity field. Since neither vertical velocities nor vertical derivatives of velocity are available, the program assumes a stress-free spherical Earth's surface and a linear viscous rheology to obtain constraints on the unavailable tensor components. With these assumptions, two eigenvectors of the strain rate tensor are parallel to the Earth's surface and one points perpendicular to it. If, in addition, vertical velocity is negligible, the surface-parallel eigenvectors can be calculated from the horizontal velocity components only. Figure 13 shows the resulting extensional and compressional principal directions of strain rate in the southeastern Aegean. The former ones compare very well with a similar result obtained by Floyd et al. (2010).

Comparison of principal stress and strain rate axes yields the following results: for cluster regions with distinct tensional stress axes and near-vertical compressional stress axes, azimuths of principal directions of tensional stress and extensional strain rate are very similar (Table 2). The largest deviation is $37^{\circ}$ for the cluster north of Karpathos. Moreover, for clusters with inclined or subhorizontal compressional stress axes (Zante and S-Karpathos), the azimuths of the compressional principal stress axes compare well with those of compressional strain rate with deviations of about $30^{\circ}$. In view of the errors of the determined stress field and the fact that the strain rate field in the southern Aegean is an interpolation of rather sparse velocity observations, these deviations appear acceptable. The only regions where strain rate differs significantly from deviatoric stress are the volcanic areas around Columbo, Astypalea and Kos-Nisyros. They exhibit a well-constrained near-vertical compressional stress axis but no distinct tensional axes. In contrast, extensional strain rate in these regions is much greater than compressional strain rate. Apparently, volcanic activity creates local stresses that also control the character of seismicity.
Table 2. Comparison of azimuths of tensional/compressional principal stress axes with extensional/compressional principal axes of strain rate for shallow earthquake clusters.

\begin{tabular}{lrr}
\hline Cluster & $\begin{array}{r}\text { Azimuth/deg } \\
\text { tensional } \\
\text { stress }\end{array}$ & $\begin{array}{r}\text { Azimuth/deg } \\
\text { extensional } \\
\text { strain rate }\end{array}$ \\
\hline Amorgos & 155 & 162 \\
Mykonos & 309 & 296 \\
Sigacik & 25 & 17 \\
Gökova & 20 & -4 \\
N-Karpathos & 47 & 84 \\
Iraklion & 270 & 300 \\
Kamilonisi & 72 & 100 \\
\hline Cluster & Azimuth/deg & Azimuth/deg \\
& compressional & compressional \\
& stress & strain rate \\
\hline S-Karpathos & 147 & 173 \\
Zante & 209 & 240 \\
\hline
\end{tabular}

\subsection{Stress state of the Hellenic slab from intermediate depth events}

Events located at depths greater than $50 \mathrm{~km}$ could be grouped into four different clusters (Fig. 14): Cretan Sea, Rhodos and surroundings, Cyclades and a big cluster in the Nisyros-KosAstypalea region. Table 3 summarizes the stress tensor solutions obtained for these four clusters. These clusters differ very much from the shallow ones. The compressional stress axis dips much less and is closer to horizontal than vertical. The tensional axis varies strongly and can dip very steeply. The angular misfit for the Rhodos and Cyclades events is quite large and thus reflects a violation of the assumption of a homogeneous stress field. Hence, the results for the Cyclades cluster and to a lesser degree those of the Rhodos cluster should be regarded with caution.

\subsubsection{Nisyros-Astypalea}

We were able to collect focal mechanisms for 42 earthquakes deeper than $100 \mathrm{~km}$ clustering in the Nisyros-Astypalea area. $\mathrm{T}$ and $\mathrm{P}$ axes of the focal mechanisms nicely cluster on different halves of the focal sphere (Fig. 15). The $80 \%$ closest bootstrap stress solutions exhibit a small scatter for all three principal axes. The stress ratio concentrates at a value of $R=0.4$ indicating nearly equal magnitudes for the tensional and compressional principal stresses. The compressional axis dips at an angle of $32^{\circ}$ indicating near slab-normal compression. The azimuth is rotated by $12^{\circ}$ towards the south from SE-NW. This direction only slightly deviates from the SWNE direction of subduction. The dip of the tensional axis is $47^{\circ}$, about parallel to the expected dip of the eastern part of the Hellenic slab. Its azimuth, however, only deviates by $7^{\circ}$ from straight $\mathrm{E}-\mathrm{W}$ and thus differs by $38^{\circ}$ from the presumed 

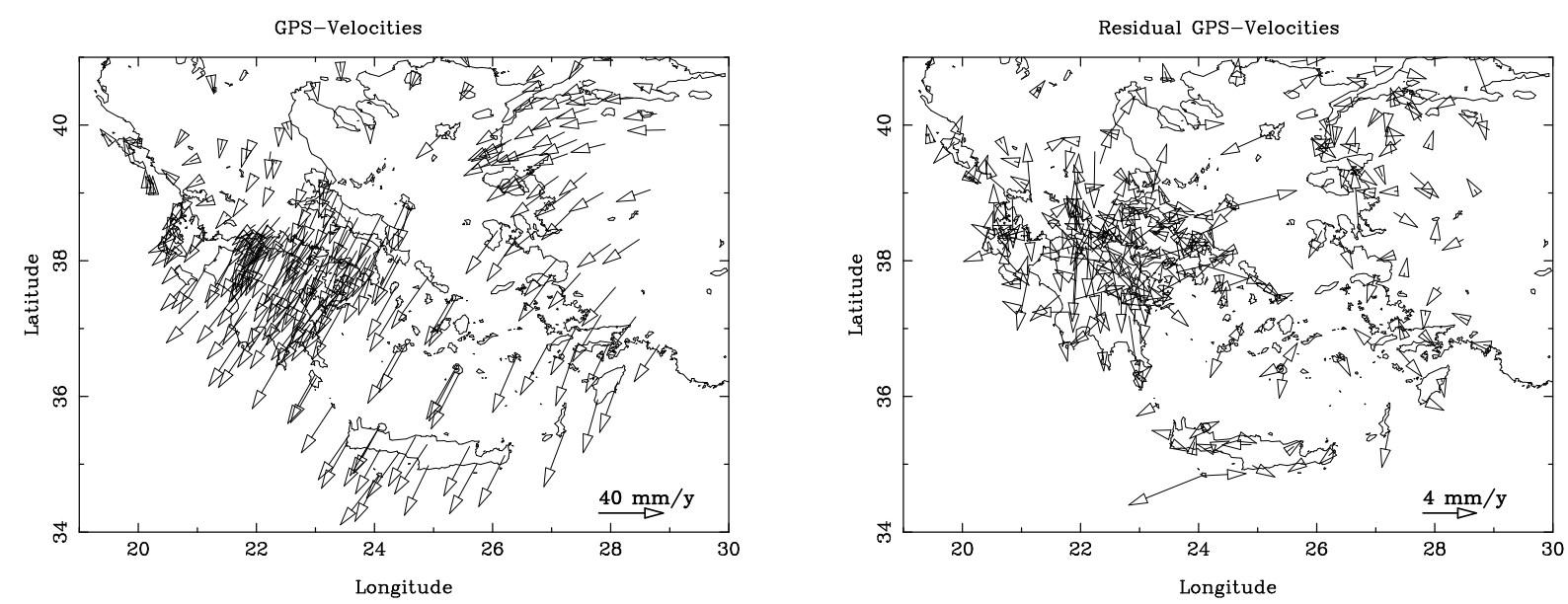

Fig. 12. Observed GPS velocities of Floyd et al. (2010) (left) and residuals between observed and interpolated continuous velocity field (right).
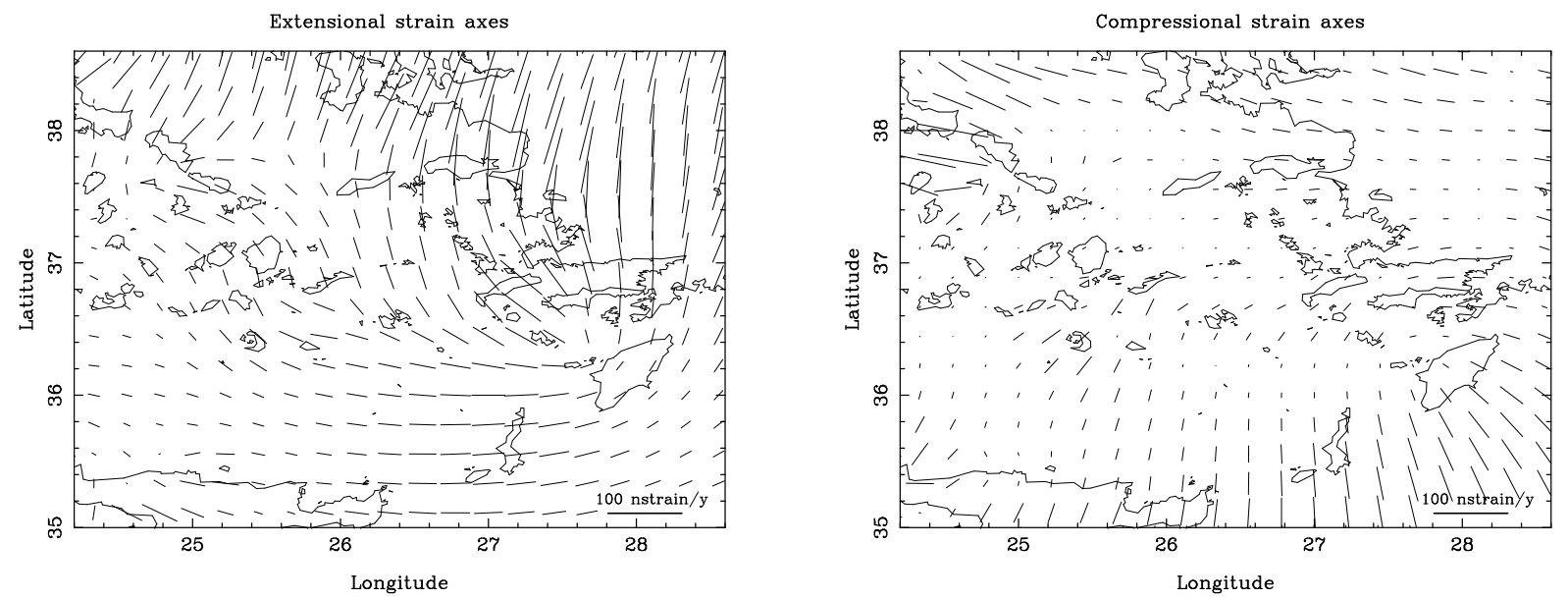

Fig. 13. Extensional (left) and compressional (right) principal directions of strain rate derived from a continuous interpolation of observed GPS velocities in the Aegean (Floyd et al., 2010).

SE-NW subduction direction. Maximum shear stress occurs at either nearly horizontal planes or very steeply dipping planes striking about SW-NE, favouring normal faulting inside the slab.

The solution for the stress field suggests that the slab experiences slab-parallel tension that is however not exactly down-dip but slightly rotated to the west. Down-dip tension has been found by Fujita and Kanamori (1981) for old slabs with low convergence velocities at the trench. Due to their increased density caused by thermal contraction they tend to sink faster than they converge at the trench. This mechanism will put the slab under down-dip tension. We speculate that the observed rotation of tensional stress relative to the down-dip direction is related to the segmentation of the Hellenic slab which dips more strongly in the east than in the west. Beneath Astypalea, hypocentres reach depths of about $180 \mathrm{~km}$ while further in the west beneath the Cyclades they only reach depths of about $140 \mathrm{~km}$. Hence, the slab is either curved in the case it is still continuous or it is torn somewhere between the Cyclades and Astypalea. This slab deformation or tearing could explain a rotation of the tensional axis to the west because the counterforce exerted by western slab parts is missing.

Rontogianni et al. (2011) give a stress tensor solution for the Hellenic slab in this region derived from focal mechanisms of 19 earthquakes at depths between $90 \mathrm{~km}$ and $180 \mathrm{~km}$. They find a N-S-oriented compressional axis dipping at $46^{\circ}$ and a slab-parallel tensional axes directed along NW-SE. Their solution is roughly consistent with ours but does not exhibit the rotation of the tensional axis towards the W-E direction. However, their solution exhibits a high angular misfit $\left(51^{\circ}\right)$ interpreted by them as indication of the heterogeneity of the stress field. In contrast, our stress solution with the tensional axis rotated towards W-E obtained from 
Table 3. Summary of stress inversion results for shallow earthquake clusters. Clusters are ordered according to the number of available focal mechanisms. Azimuth is measured in degrees from north over east.

\begin{tabular}{lrrrrrrrrr}
\hline Cluster & $\begin{array}{r}\text { Number of } \\
\text { focal } \\
\text { mechanisms }\end{array}$ & $\begin{array}{r}\text { Average } \\
\text { misfit/deg }\end{array}$ & $\begin{array}{r}\text { Dip/ } \\
\text { deg }\end{array}$ & $\begin{array}{r}\text { Azimuth/ } \\
\text { deg }\end{array}$ & $\begin{array}{r}\text { Dip/ } \\
\text { deg }\end{array}$ & $\begin{array}{r}\text { Azimuth/ } \\
\text { deg }\end{array}$ & $\begin{array}{r}\text { Dip/ } \\
\text { deg }\end{array}$ & $\begin{array}{r}\text { Azimuth/ } \\
\text { deg }\end{array}$ & $R$ \\
\hline Nisyros & & \multicolumn{2}{c}{ Tensional axis } & Interm. axis & Compr. axis & \\
Rhodos & 42 & 20.1 & 47 & 277 & 27 & 39 & 32 & 147 & 0.4 \\
Cyclades & 16 & 28.6 & 75 & 297 & 2 & 32 & 15 & 123 & 0.8 \\
Cretan Sea & 11 & 34.6 & 64 & 284 & 17 & 52 & 19 & 148 & 0.2 \\
\hline
\end{tabular}

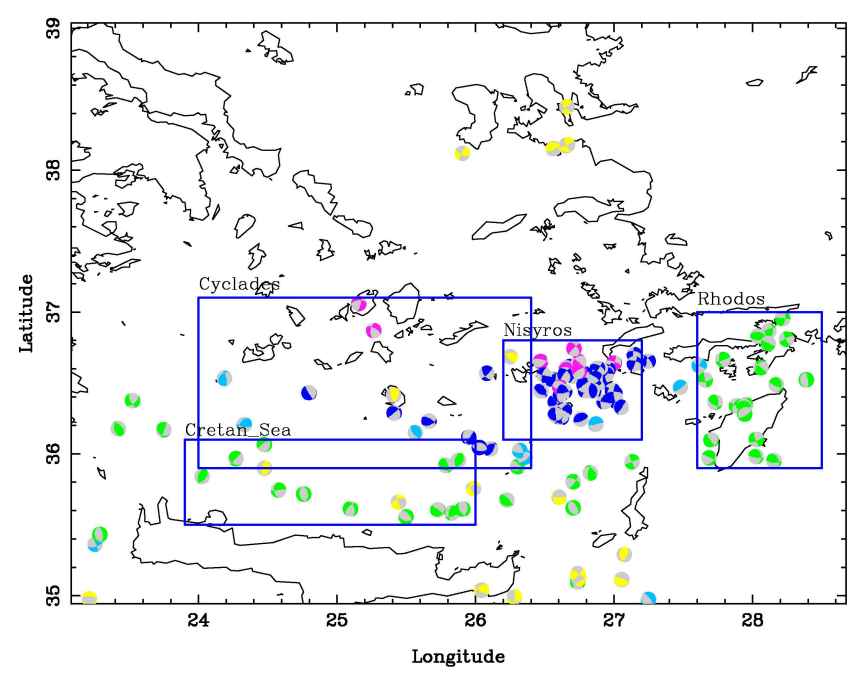

Fig. 14. Intermediate-depth earthquake locations with focal mechanisms and definition of cluster regions. The meaning of the colours of the beach balls are as given in Fig. 3 .

42 densely clustered focal mechanisms allows a match with an angular misfit of $20^{\circ}$ only.

\subsubsection{Cretan Sea}

The cluster in the Cretan Sea comprises 10 events at depths ranging from 50 to $80 \mathrm{~km}$. Their focal mechanisms can be fit very well by a single stress tensor (Fig. 16). As for the Nisyros events, the scatter of the bootstrap solutions and for the stress ratio is very small. The compressional principal axis dips at $33^{\circ}$ with an exact SE-NW orientation. The tensional axis dips at a low angle of $16^{\circ}$ pointing roughly SW$\mathrm{NE}\left(35^{\circ}\right.$ azimuth). The intermediate axis dips more strongly at $52^{\circ}$. The stress ratio of 0.3 indicates a slight dominance of compression and also a dominance of horizontal over vertical tension. Nevertheless, the stress field allows both strike slip and thrusting mechanisms.

The slab appears to be under down-dip tension and lateral compression, although the compressional axis deviates by $33^{\circ}$ from the horizontal. In addition, the SE-NW orien- tation of compression is close to but not exactly parallel to the Hellenic arc in this area which rather trends along ESEWNW. Lateral compression could be caused by reduced curvature of the slab in the segment along the island of Crete. According to the ping-pong model of Frank (1968), a slab of reduced curvature would become too "wide" laterally during subduction and thus develop compressive lateral membrane stresses. We speculate that either the rather straight shape of the island of Crete or the incipient collision with continental African lithosphere imposes this curvature reduction of the arc.

Rontogianni et al. (2011) provide a stress solution for a region encompassing Crete, the Cretan Sea and the Cyclades area based on 12 earthquakes in a depth range of $50-80 \mathrm{~km}$. They find a W-E-oriented compressional axis roughly consistent with our result. Their tensional axis is, however, nearvertical while ours is nearly horizontal and pointing SW-NE. This discrepancy illustrates the potential variability of stress solutions that are derived from only a few focal mechanisms and based on different collections of earthquakes.

The stress field in the slab beneath Rhodos (Fig. A7) and the Cyclades (Fig. A8) is much less well constrained and therefore described in the Appendix.

\section{Conclusions}

Analysis of first motions of 7000 well-located earthquakes in the southeastern Aegean recorded by the CYCNET and EGELAOS networks produced 540 well-constrained focal mechanisms. An additional 140 focal mechanism of larger events could be determined by waveform matching. Many of these earthquakes fall into spatial clusters of several tens of events permitting a local determination of the stress field from the focal mechanisms. In this way, the lateral variation of the stress field in the southern Aegean could be mapped. In addition, the intrinsic assumption of a homogeneous stress field in stress inversions is much better fulfilled for the individual clusters than for spatially distributed earthquakes.

At crustal levels the stress inversion yields steeply dipping compressional principal stress axes for nearly all clusters. Stress ratios indicate a dominance of compressional over 


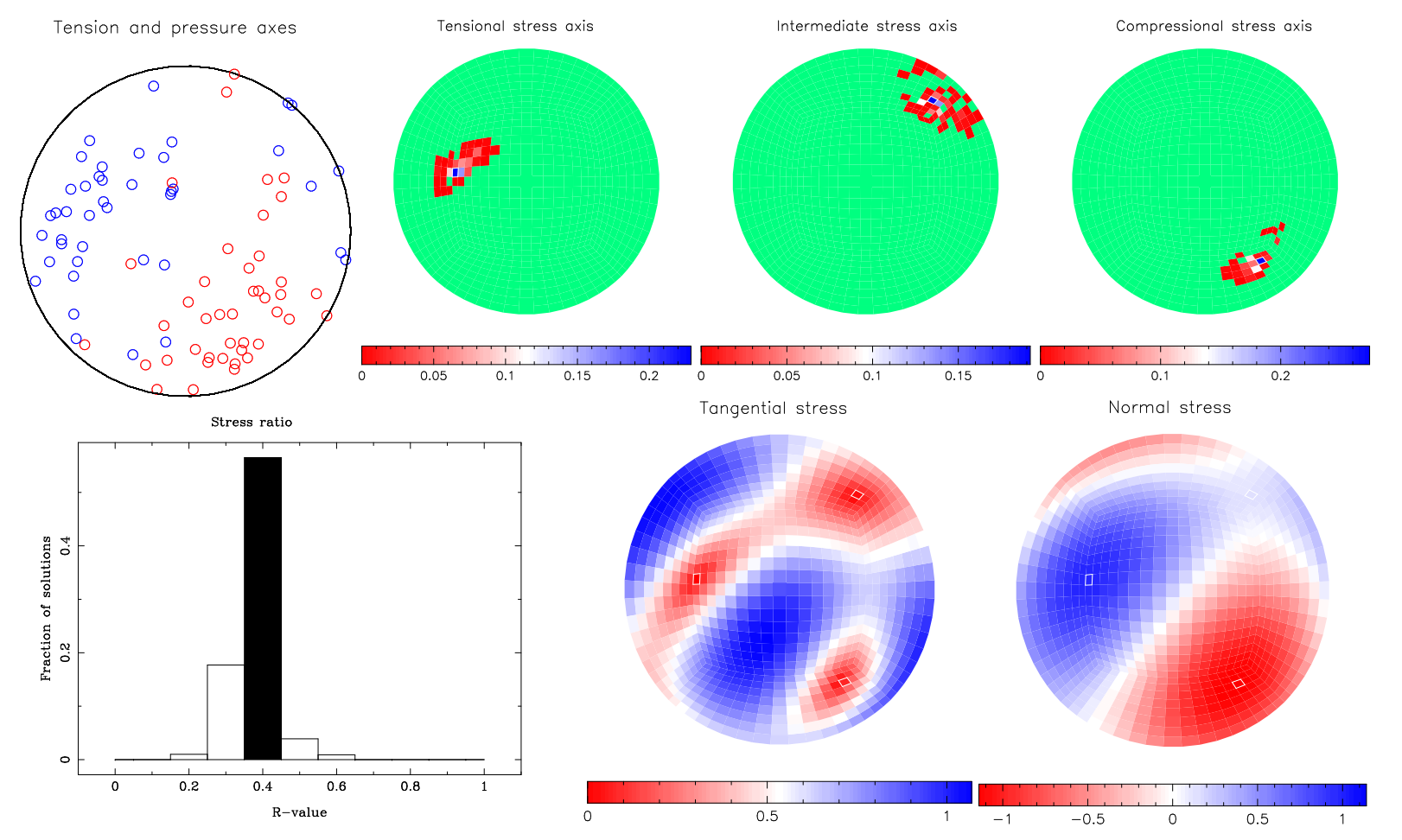

Fig. 15. Results of stress inversion for cluster of intermediate-depth earthquakes near Nisyros. Explanation of subfigures is as in Fig. 5.
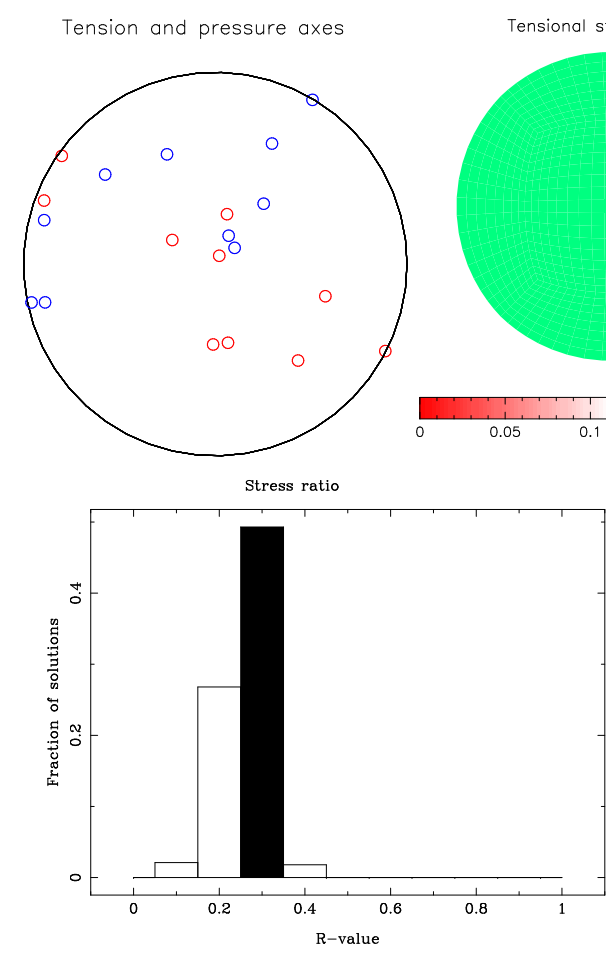

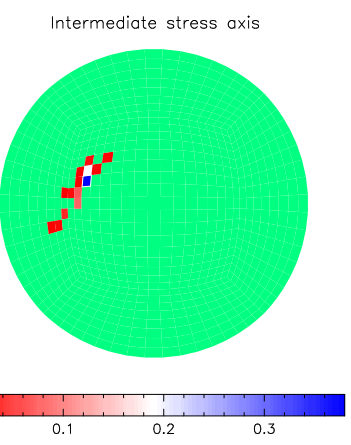

Compressional stress axis

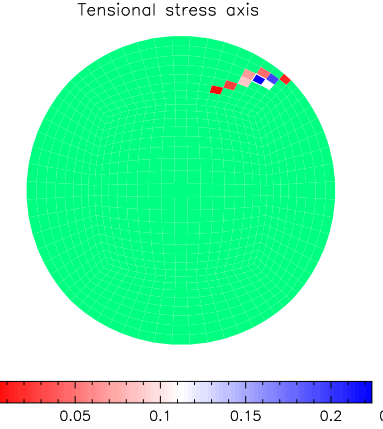

Tangential stress
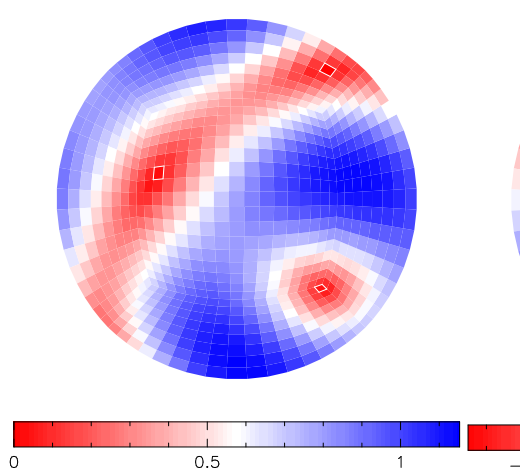

Fig. 16. Results of stress inversion for cluster of intermediate-depth earthquakes beneath the Cretan Sea. Explanation of subfigures is as in Fig. 5. 
tensional stresses. According to the behaviour of the tensional stress axis the clusters fall into three groups. For the clusters around Kos, Astypalea and Columbo in the southern volcanic arc, the tensional and intermediate principal stresses are nearly degenerate, indicating a possible magmatic source for the near-vertical compressional stresses. A very different stress regime is deduced for the Santorini-Amorgos, Gökova and Sigacik grabens where the tensional stress shows a clearly identifiable direction rotating from NW-SE in the west to NNE-SSW in the east. The tensional stress appears to stay perpendicular to the curved graben systems extending from Gökova to Amorgos and from Sigacik to Mykonos. In the area stretching from the Cretan Sea to north of Karpathos the tensional stress axes apparently follow the curvature of the Hellenic arc, indicating a control of slab rollback over the stress field there. Much less dipping compressional stress axes such as for the South Karpathos and Zante cluster reflect the tectonic influence of the subducting Hellenic slab which exerts a subhorizontal stress on the Aegean plate close to the trench.

Azimuths of principal stress axes agree very well with azimuths of principal axes of a continuous strain rate field derived by interpolation from observed GPS velocities, indicating a dominating influence of regional stress on microseismic activity. Exceptions occur in the volcanic areas around Columbo, Astypalea and Nisyros-Kos where local stresses associated with volcanic activity appear to control seismicity.

Two major clusters of intermediate-depth events allowed a determination of the stress field in the subducting plate. Beneath the Dodecanese islands the slab is roughly under down-dip tension and slab-normal compression. But the tensional stress axis is rotated by about $35^{\circ}$ to the west relative to the presumed subduction direction. This behaviour could be caused by the missing support of the western part of the slab due to segmentation or even vertical tearing along a N-S line west of Karpathos. Beneath the Cretan Sea the Hellenic slab is found to be under NW-SE compression which may be explained by a reduced curvature of the arc south of Crete owing to incipient collision of the Aegean plate with continental African lithosphere.

Acknowledgements. This study was supported by the German Research Foundation through the Collaborative Research Centre 526 "Rheology of the Earth - from the upper crust to the subduction zone". The EGELADOS experiment greatly benefited from seismic stations kindly provided by the Geophysical Instrument Pool Potsdam (GIPP). Waveform data of the CYCNET and EGELADOS experiments are openly available at the GEOFON data centre. An inspiring review by N. Houlie is acknowledged.

Special Issue: "Rheology of the Earth - observations, laboratory experiments and numerical modelling from the micro- to the macro-scale" Edited by: H. Thybo and W. Friederich

\section{References}

Aktug, B., Nocquet, J. M., Cingöz, A., Parsons, B., Erkan, Y., England, P., Lenk, O., Gürdal, M. A., Kilicoglu, A., Akdeniz, H., and Tekgül, A.: Deformation of Western Turkey from a combination of permanent and campaign GPS data: Limits to block-like behaviour, J. Geophys. Res., 114, B10404, doi:10.1029/2008JB006000, 2009.

Angelier, J.: Tectonic evolution of the Hellenic arc since the late Miocene, Tectonophysics, 49, 23-36, 1978.

Becker, D., Meier, T., Rische, M., Bohnhoff, M., and Harjes, H.-P.: Spatio-temporal microseismicity clustering in the Cretan region, Tectonophysics, 423, 3-16, 2006.

Becker, D., Meier, T., Bohnhoff, M., and Harjes, H.-P.: Seismicity at the convergent plate boundary offshore Crete, Greece, observed by an amphibian network, J. Seismol., 14, 369-392, 2009.

Benetatos, C., Kiratzi, A., Papazachos, C., and Karakaisis, G.: Focal mechanisms of shallow and intermediate depth earthquakes along the Hellenic Arc, J. Geodyn., 37, 253-296, 2004.

Bohnhoff, M., Markis, J., Papanikolaou, D., and Stavrakakis, G.: Crustal investigations of the Hellenic subduction zone using wide aperture seismic data, Tectonophysics, 343, 239-262, 2001.

Bohnhoff, M., Rische, M., Meier, T., Endrun, B., Harjes, H.-P., and Stavrakakis, G.: CYC-NET: a temporary seismic network on the Cyclades (Aegean Sea, Greece), Seismol. Res. Lett., 75, 352357, 2004.

Bohnhoff, M., Harjes, H.-P., and Meier, T.: Deformation and stress regimes in the Hellenic subduction zone from focal Mechanisms, J. Seismol., 9, 341-366, 2005.

Bohnhoff, M., Rische, M., Meier, T., Becker, D., Stavrakakis, G., and Harjes, H.-P.: Microseismic activity in the Hellenic Volcanic Arc, Greece, with emphasis on the seismotectonic setting of the Santorini-Amorgos zone, Tectonophysics, 423, 17-33, 2006.

Brüstle, A.: Seismicity of the eastern Hellenic Subduction Zone, Ph.D. thesis, Ruhr-University, Bochum, 2012.

Comninakis, P. and Papazachos, B.: Space and time distribution of the intermediate focal depth earthquakes in the Hellenic arc, Tectonophysics, 70, 35-47, 1980.

Dimitriadis, I., Panagiotopoulos, D., Papazachos, C., Hatzidimitrou, P., Karagianni, E., and Kane, I.: Recent seismic activity (1994-2002) of the Santorini volcano using data from local seismological network, Dev. Volcano., 7, 185-203, 2005.

Dimitriadis, I., Karagianni, E., Panagiotopoulos, D., Papazachos, C., Hatzdimitriou, P., Bohnhoff, M., Rische, M., and Meier, T.: Seismicity and active tectonics at Coloumbo Reef (Aegean Sea, Greece): monitoring an active volcano at Santorini Volcanic Center using a temporary seismic network, Tectonophysics, 465, 136-149, 2009.

Drakatos, G. and Latoussakis, J.: A catalog of aftershock sequences in Greece (1971-1997): their spatial and temporal characteristics, J. Seismol., 5, 137-145, 2001.

Efron, B. and Tibshirani, R.: Bootstrap methods for standard errors, confidence intervals, and other measures of statistical accuracy, Stat. Sci., 1, 54-75, 1986.

Frank, F.: Curvature of island arcs, Nature, 220, 363-363, 1968.

Friederich, W. and Dalkolmo, J.: Complete synthetic seismograms for a spherically symmetric earth by a numerical computation of the Green's function in the frequency domain, Geophys. J. Int., 122, 537-550, 1995. 
Friederich, W. and Meier, T.: Temporary seismic broadband network acquired data on Hellenic subduction zone, EOS T. Am. Geophys. Un., 89, 378-378, 2008.

Floyd, M. A., Billiris, H., Paradissis, D., Veis, G., Avallone, A. Briole, P., McClusky, S., Nocquet, J.-M., Palamartchouk, K., Parsons, B., and England, P. C.: A new velocity field for Greece: Implications for the kinematics and dynamics of the Aegean, J. Geophys. Res. ,115, B10403, doi:10.1029/2009JB007040, 2009.

Fujita, K. and Kanamori, H.: Double seismic zones and stresses of intermediate depth earthquakes, Geophys. J. Roy. Astr. S., 66, $131-156,1981$

Gephart, J. and Forsyth, D.: Improved method for determining the regional stress tensor using earthquake focal mechanism data: application to the San Fernando earthquake sequence, J. Geophys. Res., 89, 9305-9320, 1984.

Hardebeck, J. and Michael, A. L.: Stress orientations at intermediate angles to the San Andreas Fault, California, J. Geophys. Res., 109, B11303, doi:10.1029/2004JB003239, 2004.

Hardebeck, J. and Shearer, P.: A new method for determining firstmotion focal mechanisms, B. Seismol. Soc. Am., 92, 2264-2276, 2002.

Haslinger, F.: Velocity structure, seismicity and seismotectonics of northwestern Greece between the Gulf of Arta and Zakynthos, Ph.D. thesis, Eidgenössische Technische Hochschule, Zürich, No. 12966, 1998.

Hatzfeld, D., Besnard, M., Makropoulos, K., and Hatzidimitriou, P.: Microearthquake seismicity and fault-plane solutions in the southern Aegean ant its geodynamic implications, Geophys. J. Int., 115, 799-818, 1993.

Hollenstein, C., Geiger, A., Kahle, H. G., and Veis, G.: CGPS timeseries and trajectories of crustal motion along the West Hellenic Arc, Geophys. J. Int., 164, 182-191, 2006.

Hollenstein, C., Müller, M. D., Geiger, A., and Kahle, H. G.: Crustal motion and deformation in Greece from a decade of GPS measurements, 1993-2003, Tectonophysics, 449, 17-40, 2008.

Jost, M., Knabenbauer, O., Cheng, J., and Harjes, H.-P.: Fault plane solutions of microearthquakes and small events in the Hellenic arc, Tectonophysics, 356, 87-114, 2002.

Kahle, H.-G., Concord, M., Peter, Y., Geiger, A., Reilinger, R., Barka, A., and Veis, G.: GPS derived strain rate field within the boundary zones of the Eurasian, African, and Arabian plates, Geophys. J. Int., 105, 23353-23370, 2000.

Kiratzi, A. and Papazachos, C. B.: Active deformation of the shallow part of the subducting lithospheric slab in the southern Aegean, J. Geodyn., 19, 65-78, 1995.

Kiratzi, A., Benetatos, C., and Roumelioti, Z.: Distributed earthquake focal mechanisms in the Aegean Sea, Bull. Geol. Soc. Greece, 40, 1125-1137, 2007.

Kissling, E., Ellsworth, W. L. Eberhart-Phillips, D., and Kradolfer, U.: Initial reference models in local earthquake tomography, J. Geophys. Res., 99, 19635-19646, 1994.

Lomax, A. and Curtis, A.: Fast, probabilistic earthquake location in 3D models using Oct-Tree Importance sampling, Geophys. Res. Abstr., 3, 2001.

Lomax, A., Michelini, A., and Curtis, A.: Earthquake location, direct, global-search methods, in: Encyclopedia of Complexity and System Science, Part 5, edited by: Meyers, R., Springer, New York, 2449-2473, 2009.
McClusky, S., Balassanian, S., Barka, A., Demir, C., Ergintav, S., Georgiev, I., Gurkan, O., Hamburger, M., Hurs, K., Kahle, H., Kastens, K., Kekelidze, G., King, R., Kotzev, V., Lenk, O., Mahmoud, S., Mishin, A., Nadariya, M., Ouzounis, A., Paradissis, D., Peter, Y., Prilepin, M., Reilinger, R., Sanli, I., Seeger, H., Tealeb, A., Toksoez, M., and Veis, G.: Global Positioning System constraints on plate kinematics and dynamics in the eastern Mediterranean and Caucasus, J. Geophys. Res., 105, 5695-5719, 2000.

McKenzie, D.: The relation between fault plane solutions for earthquakes and the directions of the principal stresses, B. Seismol. Soc. Am., 59, 591-601, 1969.

Meier, T., Dietrich, K., Stöckert, B., and Harjes, H.-P.: Onedimensional models of shear-wave velocity for eastern Mediterranean obtained from the inversion of Rayleigh wave phase velocities and tectonic implications, Geophys. J. Int., 156, 45-58, 2004.

Michael, A.: Determination of stress from slip data: faults and folds, J. Geophys. Res., 89, 11517-11526, 1984.

Michael, A. J.: Use of focal mechanisms to determine stress: a control study, J. Geophys. Res., 92, 357-368, 1987.

Papadimitriou, P., Kaviris, G., Karakonstantis, A., and Makropoulos, K.: The Cornet seismological network: 10 years of operation,recorded seismicity and significant applications, Hellenic J. Geosci., 45, 193-208, 2010.

Papazachos, B.: Seismicity of the Aegean and surrounding area, Tectonophysics, 178, 287-308, 1990.

Papazachos, B. and Delibasis, N.: Tectonic stress field and seismic faulting in the area of Greece, Tectonophysics, 7, 231-255, 1969.

Papazachos, B., Kiratzi, A., Hatzidimitriou, P., and Rocca, A.: Seismic faults in the Aegean area, Tectonophysics, 106, 71-85, 1984

Papazachos, B., Kiratzi, A., and Papadimitriou, E.: Regional focal mechanisms for earthquakes in the Aegean area, Pageoph, 136, 405-420, 1991.

Papazachos, B., Comninakis, P., Scordilis, E., Karakaisis, G., and Papazachos, C.: A catalogue of earthquakes in the Mediterranean and surrounding area for the period 1901 - Sept 2009, Publ. Geophys. Laboratory, University of Thessaloniki, 2009.

Reilinger, R., McClusky, S., Vernant, P., Lawrence, S., Ergintav, S., Cakmak, R., Ozener, H., Kadirov, F., Guliev, I., Stepanyan, R., Nadyriya, M., Hahubia, G., Mahmoud, S., Sakr, K., ArRajehi, A., Paradissis, D., Al-Aydrus, A., Prilepin, M., Guseva, T., Evren, E., Dmitrotsa, A. Filikov, S., Gomez, F., AlGhazzi, R., and Karam, G.: GPS constraints on continental deformation in the African-Arabian-Eurasia continental collision zone and implications for the dynamics of plate interactions, $\mathrm{J}$. Geophys. Res., 111, B05411, doi:10.1029/2005JB004051, 2006.

Reilinger, R., McClusky, S., Paradissis, D., Ergintav, S., and Vernant, P.: Geodetic constraints on the tectonic evolution of the Aegean region and strain accumulation along the Hellenic subduction zone, Tectonophysics, 488, 22-30, 2010.

Rigo, A., Lyon-Caen, H., Armijo, R., Deschamps, A., Hatzfeld, D., Makropoulos, K., Papadimitriou, P., and Kassaras, I.: A microseismic study in the western part of the Gulf of Corinth (Greece): implications for large-scale normal faulting mechanisms, Geophys. J. Int., 126, 663-688, 1996.

Rontogianni, S., Konstantinou, K. I., Melis, N. S., and Evangelidis, C. P.: Slab stress field in the Hellenic subduction zone as in- 
ferred from intermediate-depth earthquakes, Earth Planets Space, 63, 139-144, 2011.

Sachpazi, M., Hirn, A., Nercessian, A., Avedik, F., Mc Bride, J., Loucoyannakis, M., Nicolich, R., and the STREAMERSPROFILES group: A first coincident normal-incidence and wideangle approach to studying the extending Aegean crust, Tectonophysics, 270, 301-312, 1997.

Tape, C., Musé, P., Simons, M., Dong, D., and Webb, F.: Multiscale estimation of GPS velocity fields, Geophys. J. Int., 179, 945-971, 2009.
Taymaz, T., Jackson, J., and McKenzie, D.: Active tectonics of the north and central Aegean Sea, Geophys. J. Int., 106, 433-490, 1991.

Wells, D. L., and Coppersmith, K. J.: New empirical relationships among magnitude, rupture length, rupture width, rupture area, and surface displacement, Bull. Seis. Soc. Am., 84, 974-1002, 1994. 


\section{Appendix A}

\section{Stress solutions for further cluster regions}

\section{A1 Kos and Astypalea}

Similar results as for the cluster at Columbo volcano were obtained for the shallow clusters near Kos and Astypalea (Figs. A1 and A2). The compressional stress axis dips steeply and the distribution of the bootstrap solutions is well focused. With respect to the other two axes, the bootstrap solutions exhibit a wide spread. In addition, and contrary to the Columbo case, there is a spread of $R$ values as well. The best fitting solutions yield $R=0$. With the same restrictions as for the Columbo case, one could speculate here as well about a magmatic contribution to the earthquake activity because the Kos-Astypalea region is located right above the intermediate-depth seismicity associated with the eastern part of the Hellenic slab.

\section{A2 Iraklion and Kamilonisi basin}

The stress solutions for these two regions (Figs. A3 and A4) show dominating subhorizontal tensional principal stress and again nearly subvertical compressional stress. The stress ratio is around 0.7 to 0.8 . For the Iraklion basin, all stress axes are fairly well determined but $R$ values show a large spread with the majority of values greater than 0.5 . The tensional stress axis is oriented W-E indicating horizontal extension and again a normal faulting regime. Planes of maximum shear stress strike $\mathrm{N}-\mathrm{S}$ and are either near-vertical or near-horizontal. For the Kamilonisi region, only the tensional axis is well determined. Its direction is rotated counterclockwise by about $20^{\circ}$ to WSW-ENE. The strike of planes of maximum shear stress is rotated in the same way and the dip is around $45^{\circ}$. Interpretation of these results should be done with caution because of the small number of available focal mechanisms.

\section{A3 Sigacik basin}

The stress field in the Sigacik basin exhibits nearly degenerate intermediate and compressional principal stresses (Fig. A5) and a dominating and very clearly constrained horizontally oriented tensional stress axis striking NNE-SSW. This is the same direction that was found for the tensional axis in the Gökova graben. Planes of maximum shear stress have intermediate dip and are oriented about WNW-ESE. The reason for the tensional stress could again be the northward motion of western Turkey relative to the central Aegean as observed by recent GPS measurements (Reilinger et al., 2010).

\section{A4 Andros-Mykonos}

A cluster of shallow earthquakes was observed along the islands of Andros, Tinos and Mykonos characterized mainly by normal faulting events. The stress determination works extraordinarily well with an average misfit of only $7.4^{\circ}$ (Fig. A6). All three principal stress axes have small $80 \%$ confidence regions. The stress ratio is also well constrained around values of 0.3 . Thus, a meaningful tensional stress axis can also be defined pointing about NW-SE. The compressional axis dips very steeply at $75^{\circ}$. Planes of maximum shear stress strike around SW-NE with intermediate to strong dip. The stress solution indicates a tensional tectonic stress in that part of the Aegean microplate in the NW-SE direction.

\section{A5 Rhodos}

For the intermediate-depth events of the Rhodos cluster (Fig. A7), the stress field is less well constrained as the angular misfit is rather large $\left(28.6^{\circ}\right)$ and the distribution of $R$ values of the bootstrap solutions is very broad. In addition, only the tensional axis appears to be well constrained at a dip of $75^{\circ}$. This value is much greater than the gentle dip of the slab in the Rhodos region as indicated by depth profiles of micro-seismicity (Brüstle, 2012). A similar observation was made by Kiratzi and Papazachos (1995) who analysed focal mechanisms of large intermediate-depth earthquakes along the Hellenic arc. The compressional and intermediate principal stresses are close to degenerate $(R=0.8)$ and exhibit a very small dip. With an azimuth of $42^{\circ}$ the intermediate stress axis which is also compressional points approximately arc-parallel and thus lies in the slab plane.

\section{A6 Cyclades}

The stress solution for the intermediate-depth Cyclades cluster (Fig. A8) even more suggests that the stress homogeneity condition is violated. The area covered by the selected earthquakes is too large and stress in the subducting slab in this region is potentially heterogeneous. The angular misfit is rather large in spite of the small number of events, neither axis is well constrained and the distribution of stress ratio values is very wide. We therefore refrain from further analysis and interpretation of the stress solution for this cluster. More fault plane solutions are needed to allow a further subdivision of this region. 

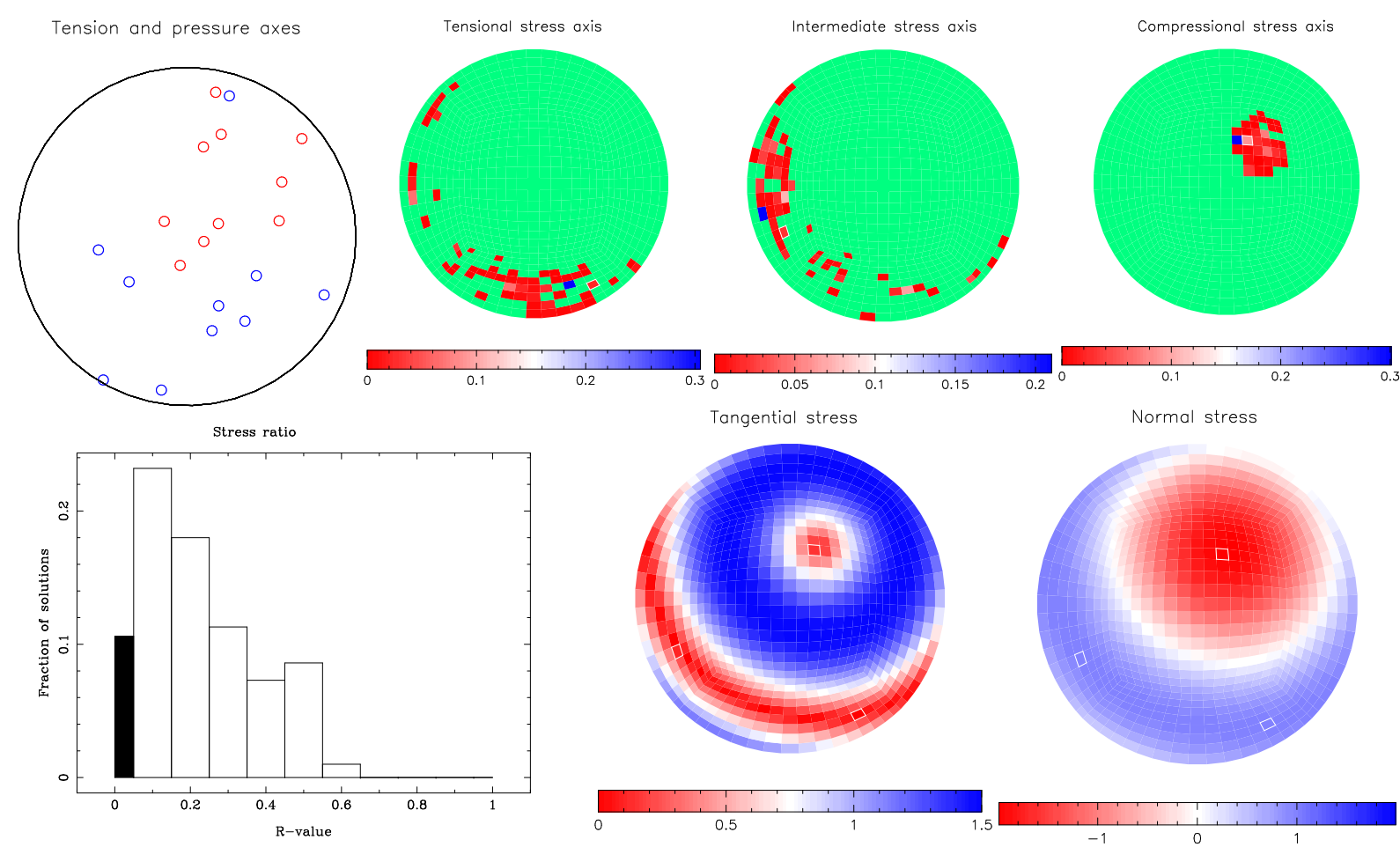

Fig. A1. Results of stress inversion for cluster of shallow earthquakes near Kos. Explanation of subfigures is as in Fig. 5.
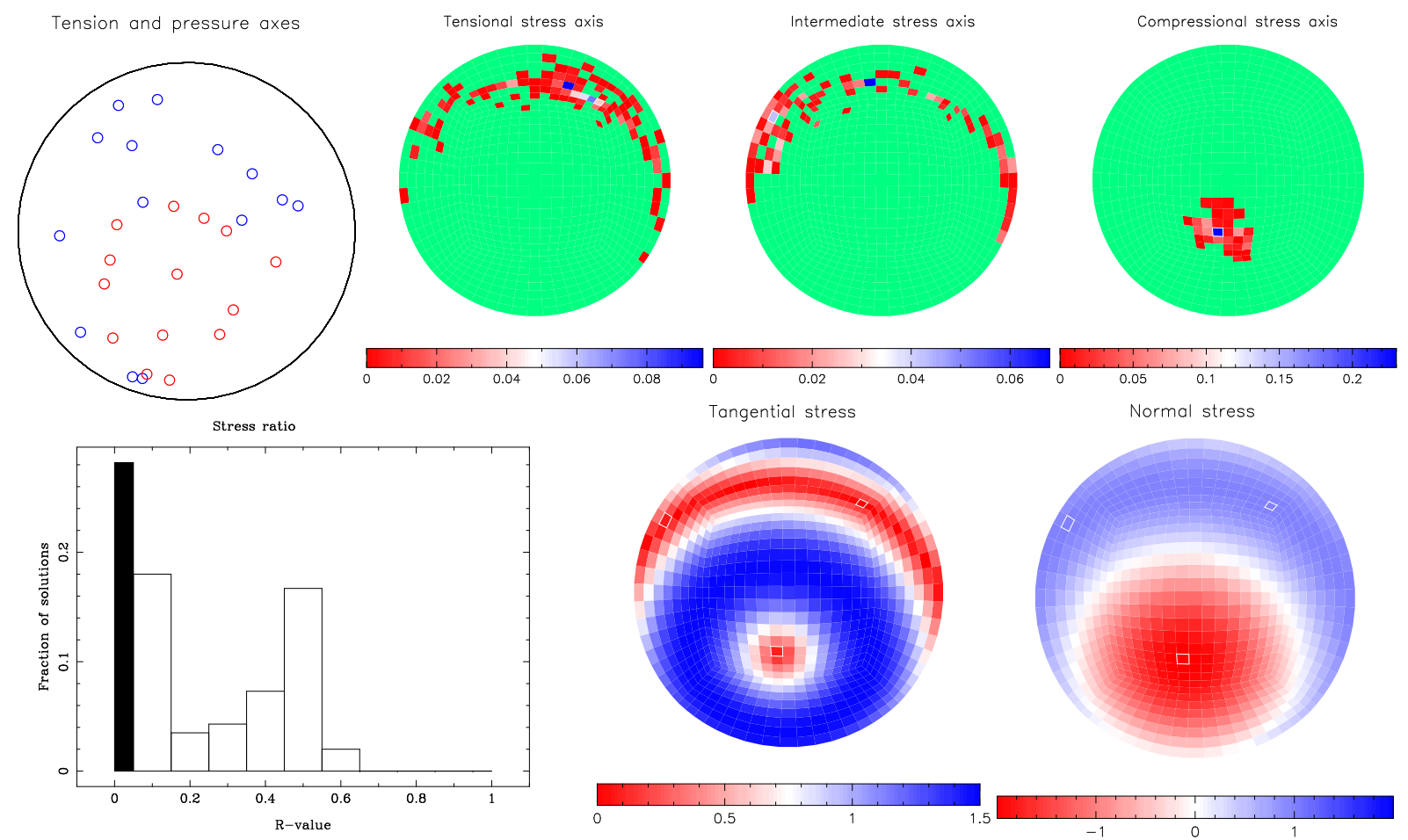

Fig. A2. Results of stress inversion for cluster of shallow earthquakes near Astypalea. Explanation of subfigures is as in Fig. 5. 

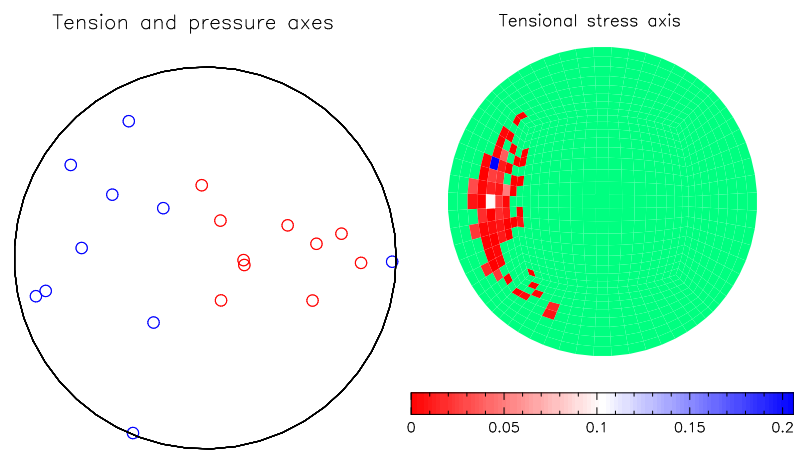

Stress ratio

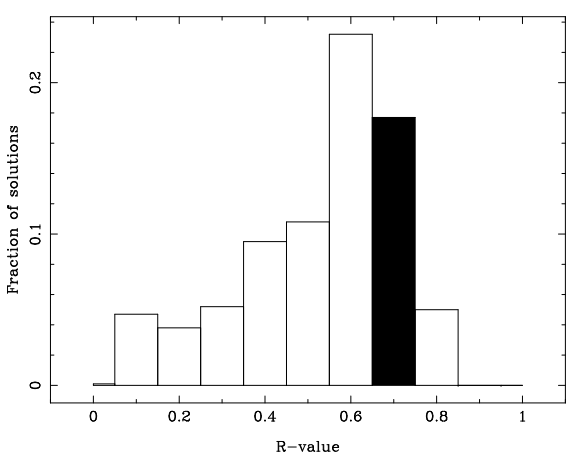

Intermediate stress axis
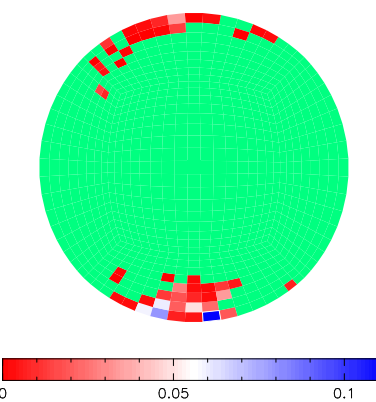

Tangential stress

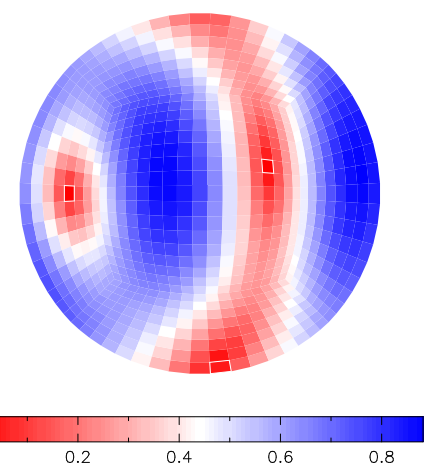

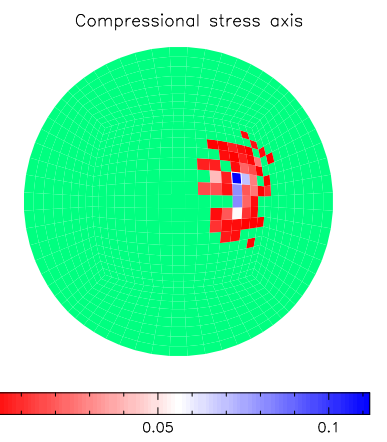

Normal stress

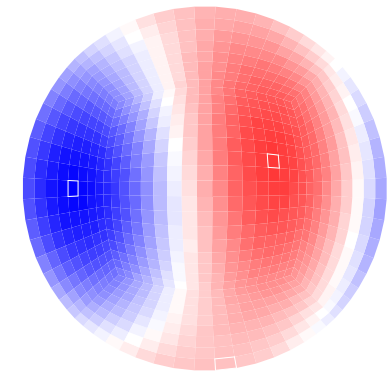

$-0.5$

Fig. A3. Results of stress inversion for cluster of shallow earthquakes in the Iraklion basin. Explanation of subfigures is as in Fig. 5.

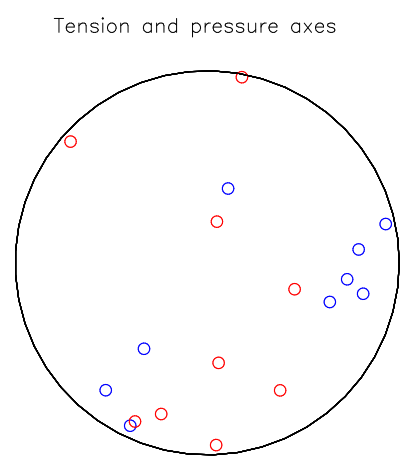

Stress ratio

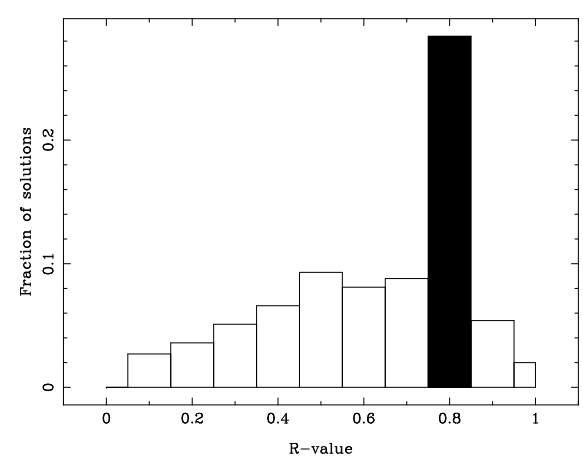

Tensional stress axis
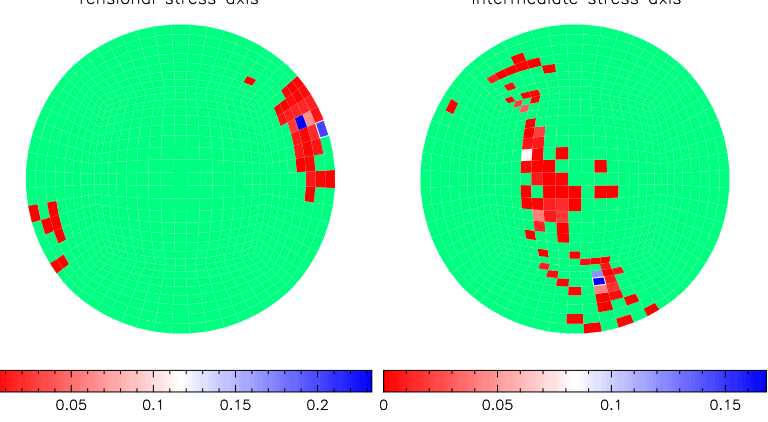

Tangential stress
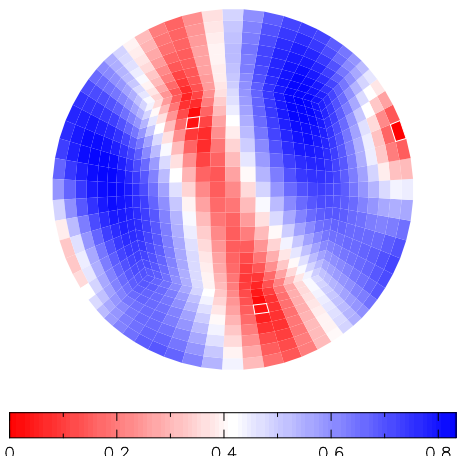

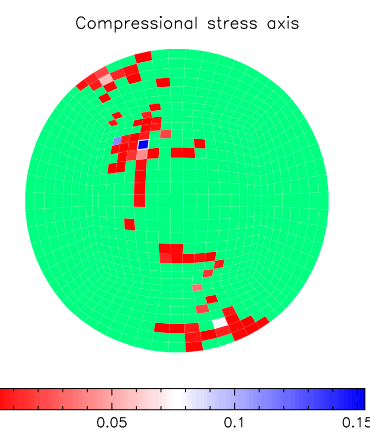

Normal stress

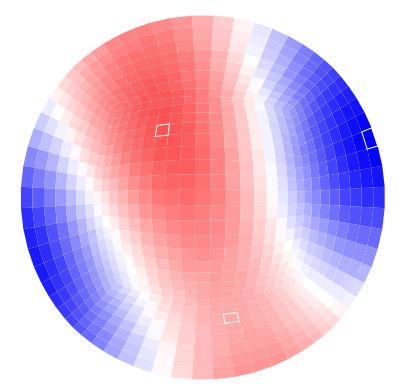

$-0$

0.5

Fig. A4. Results of stress inversion for cluster of shallow earthquakes in the Kamilonisi basin. Explanation of subfigures is as in Fig. 5. 

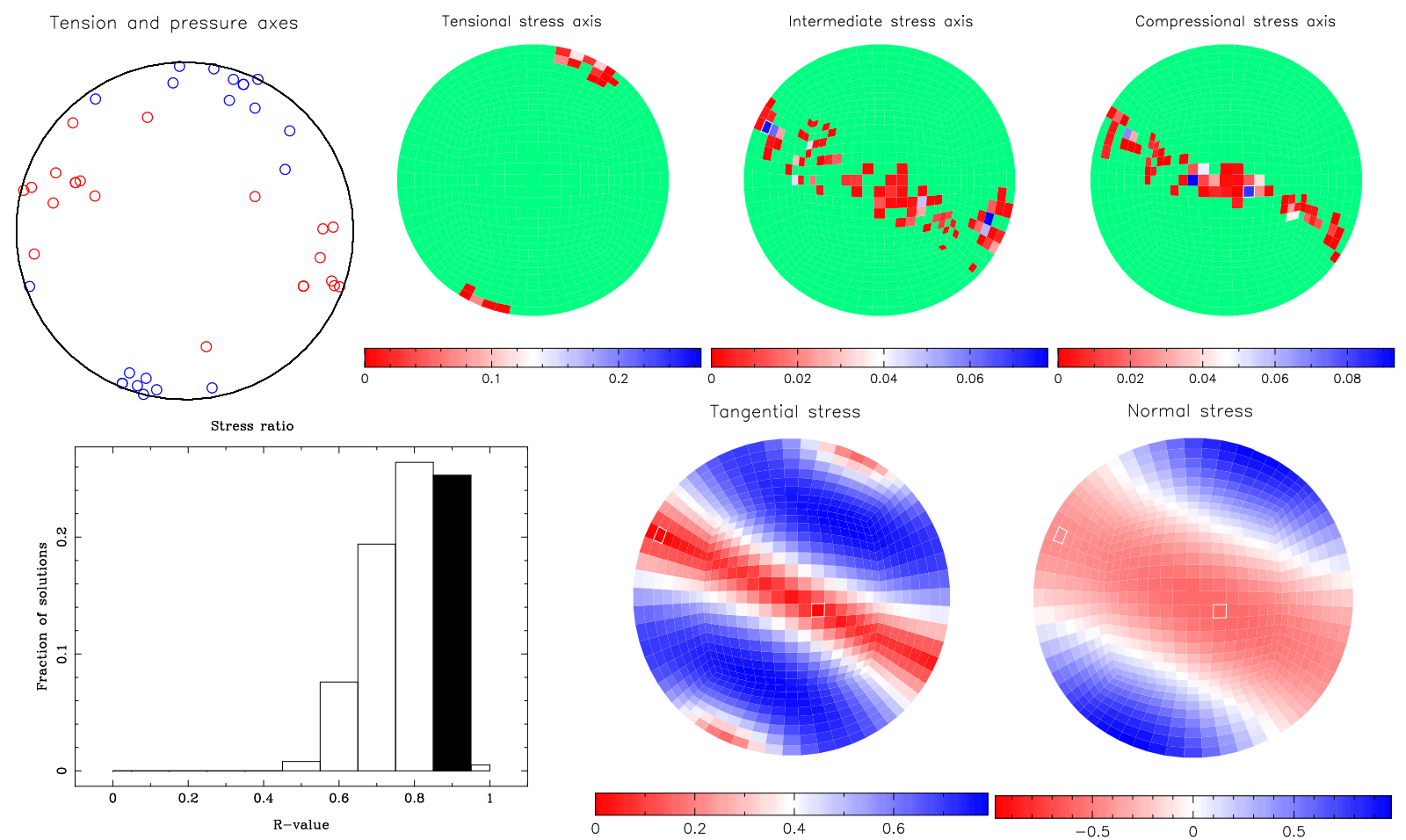

Fig. A5. Results of stress inversion for cluster of shallow earthquakes near Sigacik. Explanation of subfigures is as in Fig. 5.

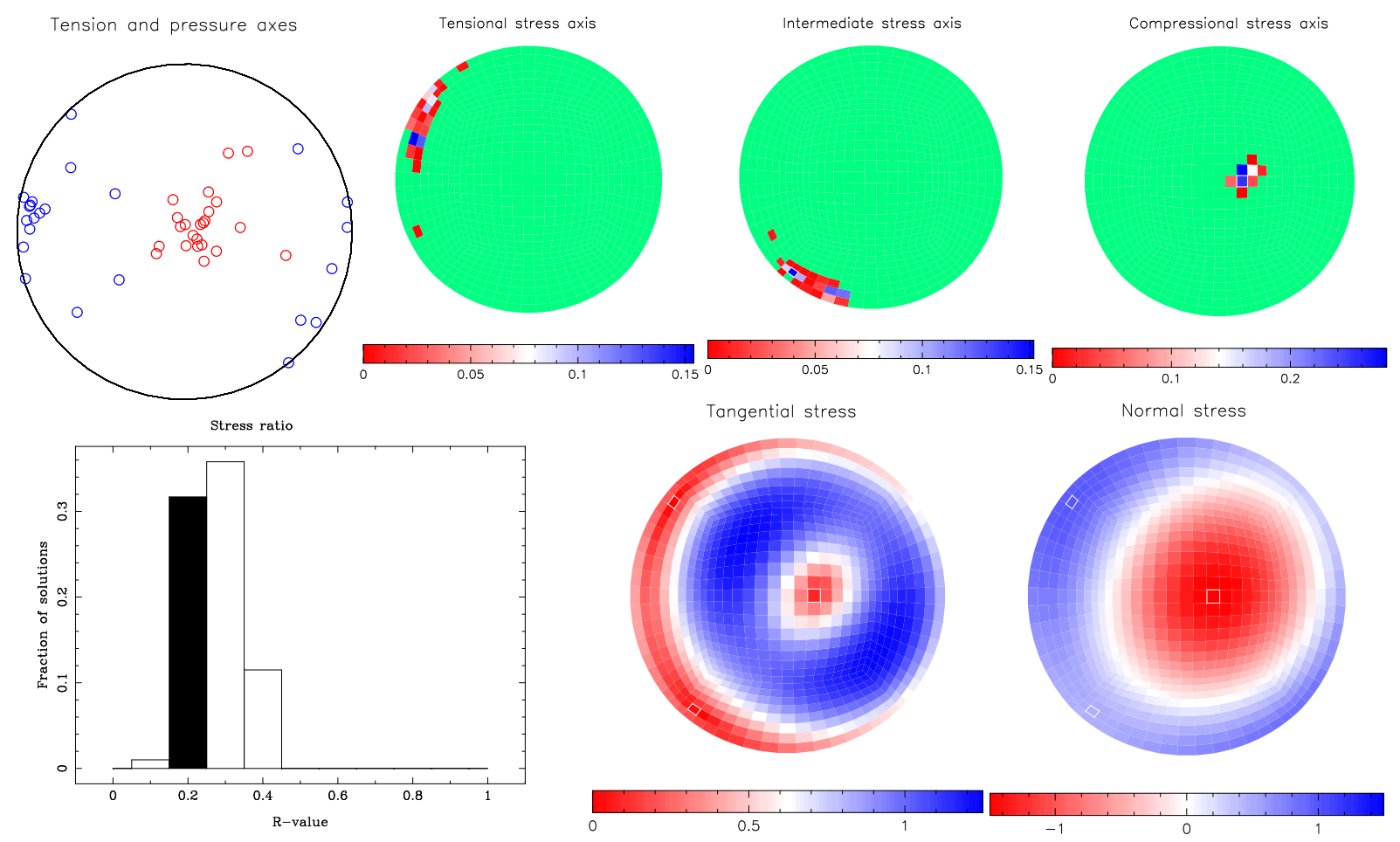

Fig. A6. Results of stress inversion for cluster of shallow earthquakes near Mykonos. Explanation of subfigures is as in Fig. 5. 

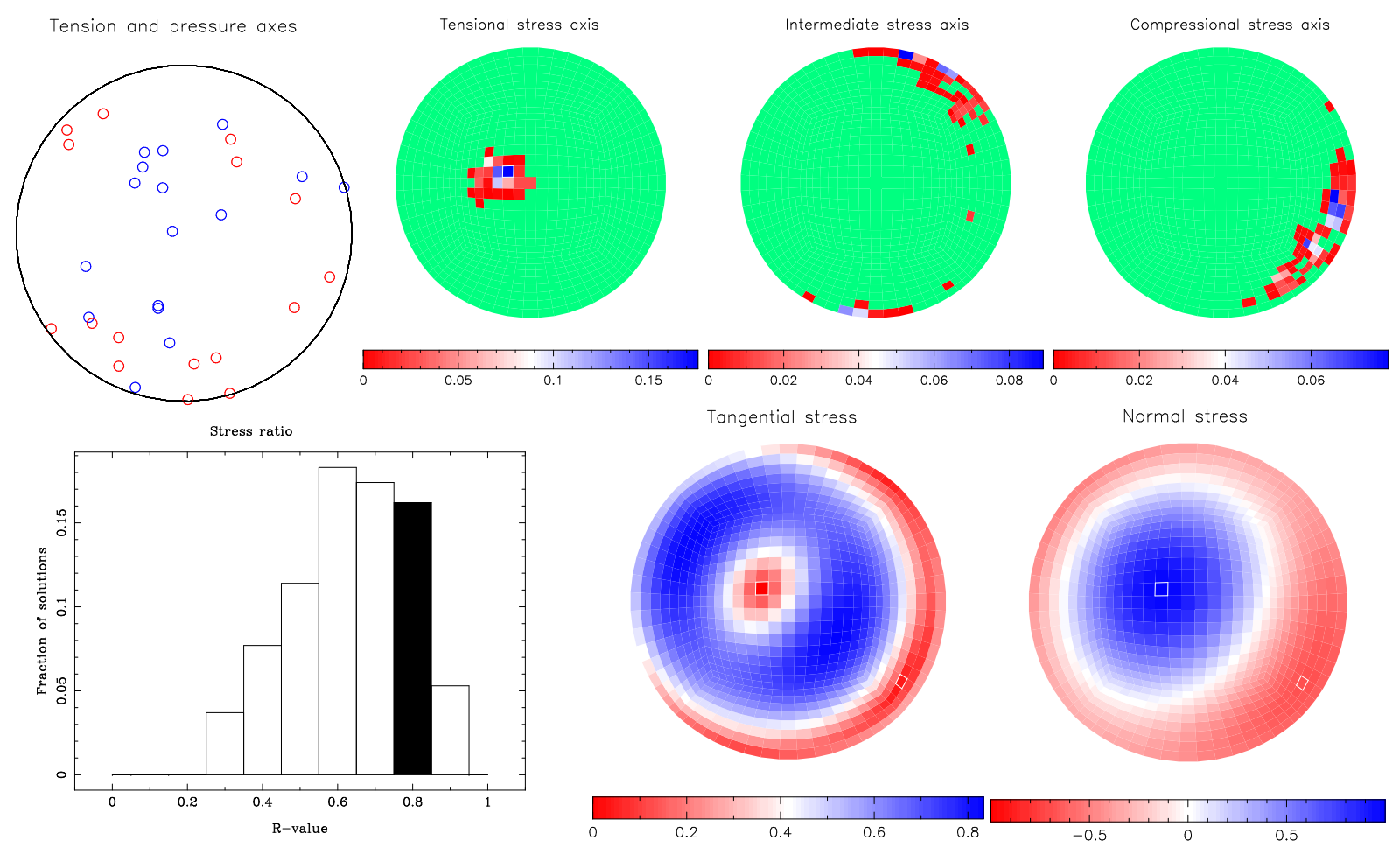

Fig. A7. Results of stress inversion for cluster of intermediate-depth earthquakes near Rhodos. Explanation of subfigures is as in Fig. 5.
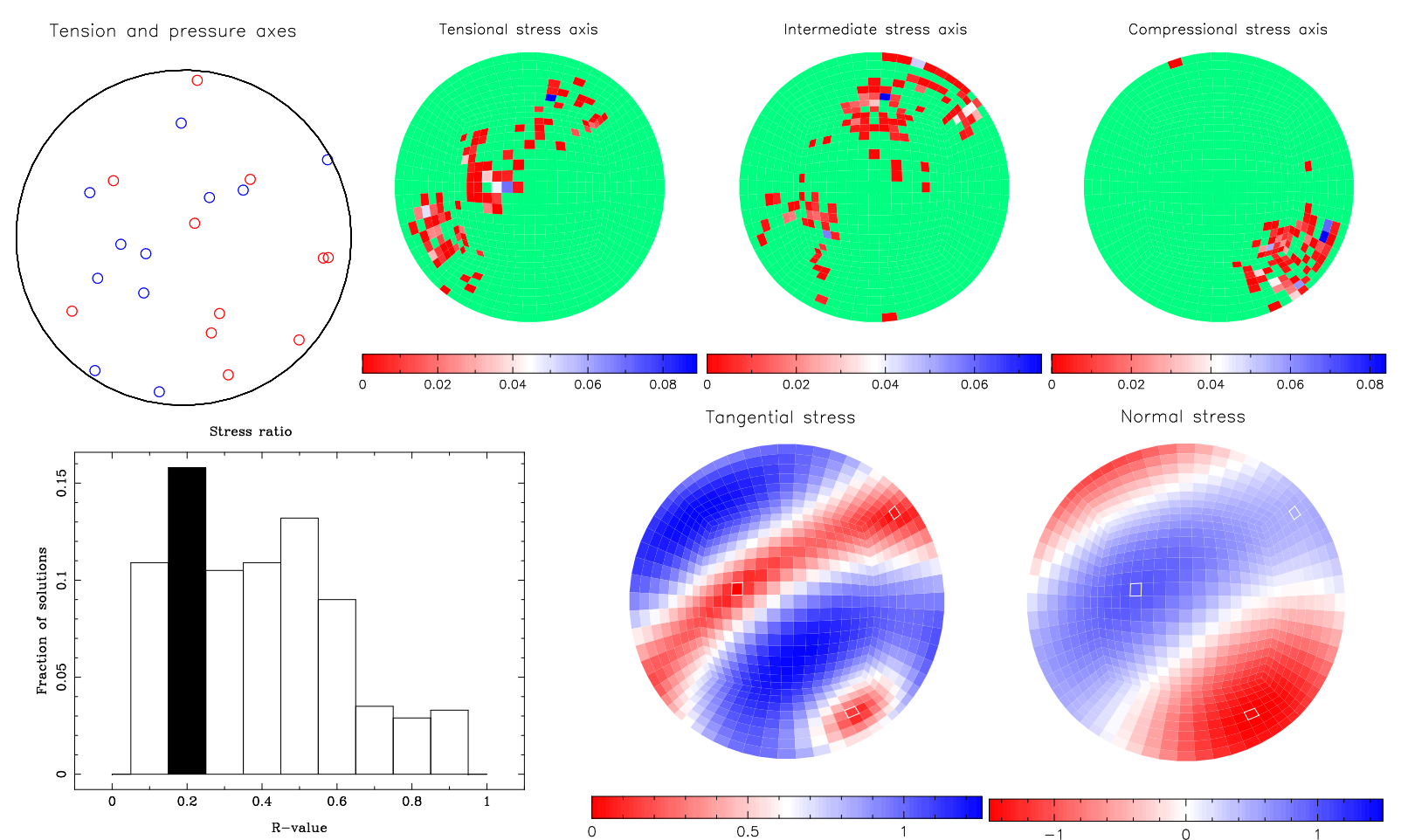

Fig. A8. Results of stress inversion for cluster of intermediate-depth earthquakes beneath the Cyclades. Explanation of subfigures is as in Fig. 5. 